\title{
The Influences of Effective Inflow Layer Streamwise Vorticity and Storm-Relative Flow on Supercell Updraft Properties
}

\author{
JOHN M. PETERS \\ Department of Meteorology, Naval Postgraduate School, Monterey, California \\ CHRISTOPHER J. NOWOTARSKI \\ Department of Atmospheric Sciences, Texas A\&M University, College Station, Texas \\ JAKE P. MULHOLLAND \\ Department of Meteorology, Naval Postgraduate School, Monterey, California \\ RICHARD L. THOMPSON \\ NOAA/NWS/NCEP/Storm Prediction Center, Norman, Oklahoma
}

(Manuscript received 31 December 2019, in final form 29 April 2020)

\begin{abstract}
The relationship between storm-relative helicity (SRH) and streamwise vorticity $\omega_{s}$ is frequently invoked to explain the often robust connections between effective inflow layer (EIL) SRH and various supercell updraft properties. However, the definition of SRH also contains storm-relative (SR) flow, and the separate influences of SR flow and $\omega_{s}$ on updraft dynamics are therefore convolved when SRH is used as a diagnostic tool. To clarify this issue, proximity soundings and numerical experiments are used to disentangle the separate influences of EIL SR flow and $\omega_{s}$ on supercell updraft characteristics. Our results suggest that the magnitude of EIL $\omega_{s}$ has little influence on whether supercellular storm mode occurs. Rather, the transition from nonsupercellular to supercellular storm mode is largely modulated by the magnitude of EIL SR flow. Furthermore, many updraft attributes such as updraft width, maximum vertical velocity, vertical mass flux at all levels, and maximum vertical vorticity at all levels are largely determined by EIL SR flow. For a constant EIL SR flow, storms with large EIL $\omega_{s}$ have stronger low-level net rotation and vertical velocities, which affirms previously established connections between $\omega_{s}$ and tornadogenesis. EIL $\omega_{s}$ also influences storms' precipitation and cold-pool patterns. Vertical nonlinear dynamic pressure acceleration (NLDPA) is larger at low levels when EIL $\omega_{s}$ is large, but differences in NLDPA aloft become uncorrelated with EIL $\omega_{s}$ because storms' midlevel dynamic pressure perturbations are substantially influenced by the tilting of midlevel vorticity. Our results emphasize the importance of considering EIL SR flow in addition to EIL SRH in the research and forecasting of supercell properties.
\end{abstract}

\section{Introduction}

Streamwise vorticity $\omega_{s}$, which is often diagnosed via storm-relative helicity (SRH), has long been considered to strongly influence the evolution of supercell thunderstorms. Large SRH often occurs in conjunction with substantial change in direction with height of the wind shear vector. It was recognized as early as the 1950 s that such curvature of low-level shear profiles was conducive to

Corresponding author: J. Peters, jmpeters@nps.edu severe weather (e.g., Fawbush and Miller 1954). Further studies of tornado proximity soundings by Maddox (1976) and Darkow and McCann (1977) showed that clockwiseturning shear vectors with height in the lower part of wind profiles were prevalent among tornado events. Using a theoretical approach based on the linearized equations of motion, Rotunno and Klemp (1982) and Davies-Jones (1984) argued that supercells owe their rotational characteristics to the tilting of initially horizontal $\omega_{s}$ into the vertical direction along inflowing air. A slew of numerical modeling studies over subsequent decades reaffirmed 
the connection between supercell updraft rotational attributes and the tilting of initially horizontal $\omega_{s}$ into the vertical direction (e.g., Rotunno and Klemp 1982, 1985; Klemp 1987; Weisman and Rotunno 2000; Davies-Jones 2002). More recent research has also shown that SRH in the lowest $500 \mathrm{~m}$ of the atmosphere plays a key role in tornadogenesis (e.g., Parker 2014; Coffer et al. 2017; Coffer and Parker 2017, 2018; Coffer et al. 2019).

Motivated by the research summarized in the previous paragraph, various measures of SRH have been incorporated into commonly used severe weather forecasting parameters such as the significant tornado parameter (STP; Thompson et al. 2003, 2007, hereinafter T07, 2012), the energy helicity index (EHI; Rasmussen 2003), and the supercell composite parameter (SCP; e.g., Thompson et al. 2003; Gropp and Davenport 2018). The SCP is most commonly used to determine the likelihood of a supercellular storm mode in a given environment, and the proposed modification to the SCP discussed in Gropp and Davenport (2018) determines the likelihood of the persistence of supercellular storm mode during the early evening transition. When supercells are present, the STP and EHI are most commonly used to discriminate between supercells that will produce significant tornadoes and those that will not. The measures of SRH in these parameters are intended to target a storm's effective inflow layer (EIL; e.g., T07), which is the layer of air that contains the sufficiently large convective available potential energy (CAPE) and sufficiently low convective inhibition (CIN) to drive deep buoyant convection. This targeting of the EIL implicitly assumes that the tilting of horizontal $\omega_{s}$ within the EIL is necessary for sustained low-level (e.g., below $3 \mathrm{~km}$ ) rotation in the case of the STP and EHI, and rotation anywhere within an updraft in the case of the SCP. For instance, the SCP will vanish in the absence of SRH in a storm's EIL, suggesting that the subsequent probability of a supercell forming in that environment also vanishes.

The relevancy of $\omega_{s}$ within a storm's EIL to tornado formation is well supported by dynamics studies. Though the vertical vorticity in tornadoes themselves is primarily baroclinically generated by storm outflow (e.g., Dahl et al. 2014) and surface friction (e.g., Schenkman et al. 2014; Roberts and Xue 2017), the tilting of ambient near-surface $\omega_{s}$ within a storm's inflow enhances low-level upward oriented dynamic pressure accelerations below the updraft, which facilitates the vertical stretching of near-surface vertical vorticity and consequently tornadogenesis (e.g., Coffer et al. 2017). There are also possible connections between $\omega_{s}$ within a storm's inflow and the properties of supercell updrafts above the lowest few kilometers of the atmosphere such as vertical acceleration, vertical velocity $w$, vertical vorticity $\zeta$, and updraft steadiness. For instance, previous authors have shown strong correlations between low-level SRH and the updraft maximum $\zeta$ among supercells simulated within different wind environments (e.g., Droegemeier et al. 1993). In addition, supercell updrafts often experience large upward dynamic accelerations related to their rotationally driven midlevel (e.g., above $3 \mathrm{~km}$ ) low pressure minima, which boost their middle- to upper-tropospheric vertical velocities (Weisman and Klemp 1984; McCaul and Weisman 1996; Weisman and Rotunno 2000; Peters et al. 2019). If we presume that there are direct correlations between maximum $\zeta$ and dynamic pressure acceleration (as suggested by Rotunno and Klemp 1982; Klemp 1987), then it also seems reasonable to hypothesize that storms in environments with large $\omega_{s}$ in their low-level inflow would have stronger upward dynamic pressure acceleration through a substantial portion of their updrafts, and might have faster $w$ as a consequence. Indeed, Brooks et al. (1993) and Parker (2017) showed that simulated storms with large low-level hodograph curvature and SRH featured steadier updrafts and larger $w$ than simulated storms with small low-level hodograph curvature and SRH, which suggests that lowlevel $\omega_{s}$ may play a key role in determining supercell updraft properties via a direct influence on dynamic accelerations. However, neither of these studies ruled out other possible reasons for why the variations in hodograph shape among their simulations influenced storm properties, nor did they establish direct connections between $\omega_{s}$ in the storm's EIL (as opposed to another layer above the EIL) and $\zeta$ at midlevels within the updraft. In fact, it remains unclear whether the $\zeta$ in supercells' midlevel vorticity maxima originates from initial horizontal vorticity in a storm's EIL, or from horizontal vorticity entrained and tilted somewhere above the EIL. This connection between air parcel source layers and midlevel rotation is key to establishing dynamical linkages between SRH in a storm's EIL and mid- to upper-level updraft accelerations.

The connection between low-level $\omega_{s}$ and mid- to upper-level supercell updraft properties is further obscured by the fact that SRH is, by definition, correlated with storm-relative (SR) flow, and because strong dynamical connections have been established between low-level SR flow and updraft properties. For instance, the formula for SRH may be written as 


$$
\begin{aligned}
\mathrm{SRH}_{d} & \equiv \int_{z=0}^{z=d} \mathbf{V}_{\mathrm{SR}} \cdot(\nabla \times \mathbf{V}) d z \\
& =\int_{z=0}^{z=d}\left|\mathbf{V}_{\mathrm{SR}}\right| \omega_{S} d z
\end{aligned}
$$

where $\left|\mathbf{V}_{\mathrm{SR}}\right|$ is the magnitude of the horizontal SR wind and $d$ is the depth over which SRH is computed. The connections between SRH and updraft properties in previous work may therefore reflect the component of SRH that corresponds to SR flow, rather than $\omega_{s}$. For instance, our recent work in Peters et al. (2019) showed that updrafts are wider when lowlevel SR flow is stronger, and wider updrafts are less susceptible to entrainment driven core dilution and have larger buoyancy, vertical accelerations, and vertical velocities as a consequence. Indeed, previous authors have also noted that a threshold value of low-level SR flow need be present in an environment for supercell updrafts to develop (e.g., Droegemeier et al. 1993; Thompson et al. 2003; this threshold is often cited as $10 \mathrm{~m} \mathrm{~s}^{-1}$ ), and Nowotarski and Jensen (2013) found that various measures of SR flow were better discriminators of supercell versus nonsupercellular storm types than $\omega_{s}$. Furthermore, Morrison (2017), Morrison et al. (2020), and Peters et al. (2020a) showed that narrow updrafts are more prone to a structural breakdown into discrete transient thermals, whereas wider updrafts tend to sustain a steady plumelike structure. Peters et al. (2020b) further argued that the large diameters of supercells facilitated the maintenance of a steady plumelike updraft, which potentially explains the results of Droegemeier et al. (1993) and Thompson et al. (2003). These results suggest that the predictive skill of low-level SRH in forecasting supercellular storm mode might be-at least partially-a result of SRH being strongly correlated with SR flow. Disentangling the dynamical influences of EIL SR flow and $\omega_{s}$-both of which are contained within SRH-is the primary objective of this paper.

The aforementioned gaps in our scientific understanding of supercells are distilled into the following research questions:

1) Q1: What are the separate influences of the $\omega_{s}$ and SR flow components of SRH within a supercell's EIL on the updraft's properties such as $w$, width, vertical mass flux, vertical vorticity, and vertical accelerations?

2) Q2: Does the vorticity responsible for supercells' midlevel vorticity maxima and associated dynamic low pressure originate from the storm's EIL, or somewhere above the EIL?
To address these questions, we examine the following hypotheses:

1) H1: The connections between SRH within storms' EIL and mid- to upper-tropospheric $w$ and $\zeta$ found in previous studies are primarily a result of the strong correlation between SRH and SR flow, with SR flow within the storm's EIL being the important factor in dynamically influencing mid- to upper-tropospheric updrafts rather than $\omega_{s}$ within the storm's EIL.

2) H2: The midlevel vorticity maximum and the associated dynamic pressure minimum in supercells are composed of a substantial portion of air that originates above the EIL. Consequently, tilting of midlevel horizontal vorticity substantially contributes to supercells' midlevel vorticity maxima and dynamic pressure minima.

To address our hypotheses, we use both proximity soundings from severe weather environments (section 2) and a series of numerical modeling experiments (section 3 ) to disentangle the relative contributions to updraft properties by low-level $\omega_{s}$ and low-level SR flow (section 4). Tracer analyses are used to determine the origin of the air within supercells' midlevel dynamic pressure minima (section 4). A summary, conclusions, and discussion are provided in section 5 .

\section{Analysis of proximity soundings}

We begin our investigation of Q1 and $\mathrm{H} 1$ with an analysis of the proximity sounding database of $\mathrm{T} 07$ to compare the relative roles of SR flow and $\omega_{s}$ (as well as other parameters) in discriminating supercell from nonsupercell environments. The T07 dataset contains soundings derived from the Rapid Update Cycle (RUC; Benjamin et al. 1994) near severe thunderstorm events. A total of 251 of these events were subjectively classified by T07 as nonsupercells, and 837 of these events were subjectively classified by T07 as supercells. Included with each of these soundings are estimates for the observed storm motion for that event (see T07 for a description of how storm motions were estimated). We computed SRH, layer mean $\omega_{s}$, and layer mean SR flow using both the observed storm motion and right-moving supercell motion estimates using the method of Bunkers et al. (2000). $\mathrm{SRH}$, layer mean $\omega_{s}$, and layer mean SR flow were calculated over depths of $0-1,0-2,0-3 \mathrm{~km}$ and over the depth of the EIL (as it was defined in T07). In addition, we computed bulk wind differences over the $0-1-, 0-2-, 0-3-, 0-4-, 0-5-, 0-6-, 0-7-$, and $0-8-\mathrm{km}$ layers, along with the effective bulk wind difference (EBWD) parameter introduced by T07. Each of these 


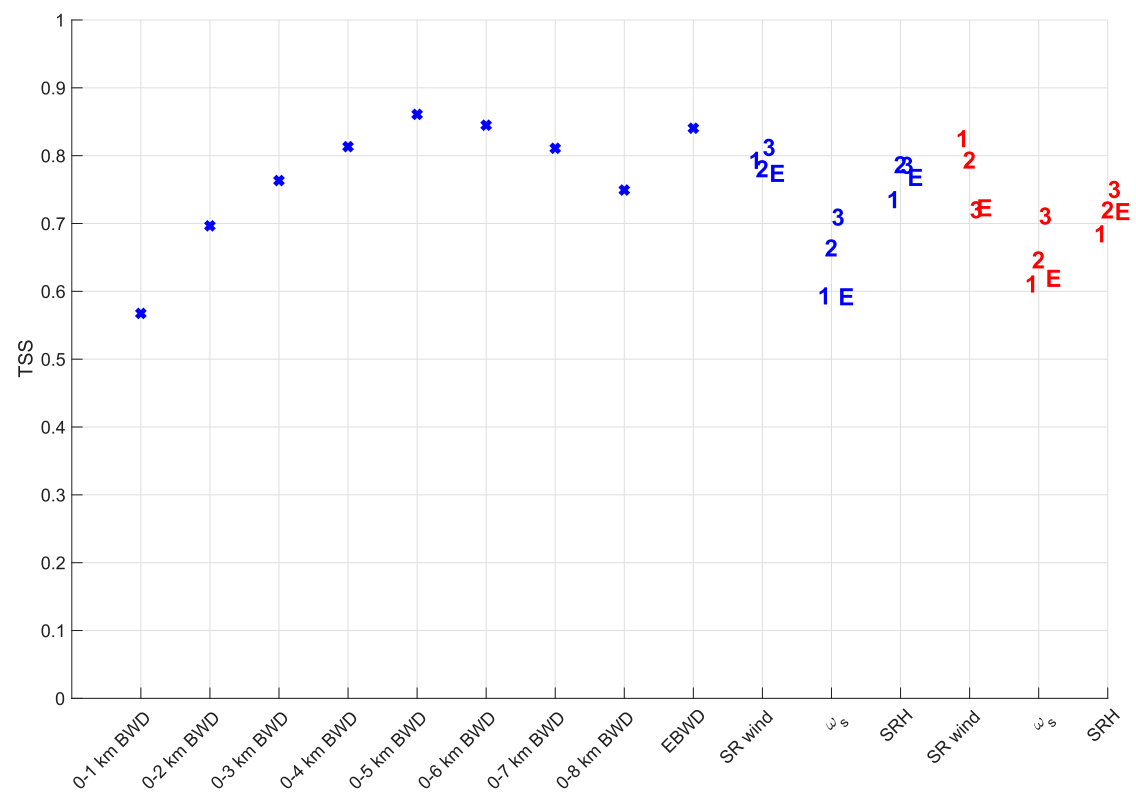

FIG. 1. TSS at predicting supercellular storm mode for different kinematic parameters computed with the observed storm motion (blue symbols) and computed with the Bunkers et al. (2000) estimate for right-mover storm motion (red symbols). For SR wind, $\omega_{s}$, and SRH, numbers denote the layer over which the quantity was computed (e.g., 1 equates to $0-1 \mathrm{~km}$ ), and "E" denotes a computation within the EIL. Note that bulk wind differences do not depend on storm motion estimates.

parameters were normalized by their standard deviation among all supercell and nonsupercell events to facilitate performance comparisons among parameters.

Following Coffer et al. (2019), we used the true skill statistic TSS $\equiv(A D-B C) /[(A+C)(B+D)]$ to assess the skill of individual parameters in discriminating between supercells and nonsupercells, where $A$ is the number of correctly predicted supercells, $B$ is the number of events for which supercells were predicted but did not happen, $C$ is the number of events for which supercells occurred but were not predicted, and $D$ is the number of correctly predicted nonsupercells. TSS approaches 1 when the probability of detection is large and the false-alarm rate is small and approaches 0 when the probability of detection is small and/or the falsealarm rate is large. We converted each nondimensional wind parameter into a binary predictor (i.e., supercell or nonsupercell) by setting a cutoff threshold, below which a nonsupercell is predicted and above which a supercell is predicted. A range of cutoff thresholds from 0 to 6 at intervals of 0.1 were tested for each parameter. In subsequent analysis, we use the cutoff threshold and depth (if applicable) for each parameter that gave the largest TSS value.

Consistent with the results of Houston et al. (2008), TSS values were generally largest for $0-5-\mathrm{km}$ bulk wind difference (BWD), 0-6-km BWD, and EBWD (Fig. 1).
For computations using both the observed and Bunkers estimated storm motions, TSS values for SR flow were, in general, slightly larger than those for SRH for a given layer. Furthermore, the layer with the best TSS value for SR flow performed statistically significantly better than the layer with the best TSS for SRH using both the observed and Bunkers storm motion estimates (Fig. 2). TSS values for both SR flow and SRH, on the other hand, were substantially larger than those for $\omega_{s}$ (Fig. 1). Furthermore, TSS values for $\omega_{s}$ averaged over given layers were more or less on par with bulk wind differences across these layers. For instance, the TSSs for $0-1$ - and $0-3-\mathrm{km}$ mean $\omega_{s}$ were similar to the TSSs for 0-1- and 0-3-km BWDs, respectively. Furthermore, the linear correlation coefficient $(\mathrm{CC})^{1}$ between $0-1$-, 0-2-, and 0-3-km mean $\omega_{s}$, and the BWDs over these respective layers was $0.89,0.82$, and 0.76 . These results suggest that low-level $\omega_{s}$ does not have any added skill over SR flow in predicting supercellular storm mode, and provides initial support for H1. Rather, the skill of

\footnotetext{
${ }^{1}$ Henceforth, the reader should assume that all CC are statistically significant at the $95 \%$ confidence level unless stated otherwise, as determined by a Student's $t$ test. Statistically insignificantly correlated quantities will be referred to as "uncorrelated." Weak, moderate, and strong refer to $\mathrm{CC}<0.5,0.5 \leq \mathrm{CC} \leq 0.75$, and $\mathrm{CC}>0.75$, respectively.
} 


\begin{tabular}{|c|c|c|c|c|c|c|c|c|c|c|}
\hline & & 0-5 km BWD & 0-6 km BWD & EBWD & SR wind & $\omega_{s}$ & SRH & SR wind & $\omega_{s}$ & SRH \\
\hline & & & & & 0 & 0 & 0 & B & B & B \\
\hline 0-5 km BWD & & - & - & - & 0.05 & 0.15 & \begin{tabular}{|l|}
0.07 \\
\end{tabular} & 0.04 & 0.15 & 0.11 \\
\hline $0-6 \mathrm{~km}$ BWD & & - & - & - & 0.03 & 0.13 & 0.06 & 0.02 & 0.13 & 0.09 \\
\hline EBWD & & - & - & - & 0.03 & 0.13 & 0.05 & 0.01 & 0.13 & 0.09 \\
\hline SR wind & 0 & (0.05) & (0.03) & (0.03) & - & 0.10 & 0.03 & - & 0.10 & 0.06 \\
\hline$\omega_{\mathrm{s}}$ & 0 & (0.15) & (0.13) & (0.13) & (0.10) & - & $(0.08)$ & $(0.12)$ & - & $(0.04)$ \\
\hline SRH & 0 & (0.07) & (0.06) & $(0.05)$ & (0.03) & 0.08 & - & $(0.04)$ & 0.08 & 0.04 \\
\hline SR wind & B & $(0.04)$ & $(0.02)$ & \begin{tabular}{|l|}
$(0.01)$ \\
\end{tabular} & - & 0.12 & 0.04 & - & 0.11 & 0.07 \\
\hline$\omega_{\mathrm{s}}$ & B & $(0.15)$ & (0.13) & (0.13) & (0.10) & - & $(0.08)$ & (0.11) & - & $(0.04)$ \\
\hline SRH & B & $(0.11)$ & $(0.09)$ & $(0.09)$ & $(0.06)$ & 0.04 & $(0.04)$ & $(0.07)$ & 0.04 & - \\
\hline
\end{tabular}

FIG. 2. Each cell represents the mean of the nondimensional quantity that labels the row minus the mean of the quantity that labels the column, computed over the layer that resulted in the largest TSS in Fig. 1. Values in parentheses are negative, differences that are not statistically significant are excluded, and colors represent the relative magnitudes of differences, with blues representing negative magnitudes and oranges representing positive values. Statistical significance was determined with a bootstrapping procedure wherein data were resampled 1000 times using random indices with the potential for repeating indices, and the mean difference between two samples was recomputed for each of the 1000 resamples. If the 95th-percentile and 5th-percentile differences were of the same sign, a difference was determined to be statistically significant. The " $\mathrm{O}$ " and " $\mathrm{B}$ " markers indicate that observed or Bunkers storm motion was used, respectively.

SRH in predicting supercellular storm mode primarily originates from the correlation of this variable with SR flow and bulk wind shear measures (CC between $0-1-$, $0-2-$, and $0-3-\mathrm{km}$ SRH and SR flow in these respective layers was $0.66,0.72$, and 0.77 ). Also worthy of note is that the 0-5- and 0-6-km and EBWD TSS values were statistically significantly larger than that for SR flow. We may attribute a large portion of the skill of these deeplayer shear metrics to their moderate-to-strong correlations with SR flow (CC ranged from 0.6 to 0.85 , depending on the SR flow layer and whether Bunkers or observed storm motion was used); however, the larger skill of the deep-layer shear metrics hints at possible connections between deep-layer shear and updraft dynamics. For instance, perhaps midlevel updraft vorticity is connected to midlevel instead of lowlevel shear in a consistent manner with our second hypothesis. These possibilities are investigated in greater detail using the simulations described in the next section.

\section{Setup for numerical experiments}

\section{a. Model configuration}

Our numerical experiments used Cloud Model 1 (CM1), version 18. CM1 is a nonhydrostatic model designed to simulate moist atmospheric processes with a single sounding serving as the model's background atmospheric state at a given time. Table 1 contains the details of the model configuration. We used the two-moment scheme of Morrison and Gettelman (2008) to parameterize microphysical processes with hail as the rimed ice species. The domain configuration generally follows that of Peters et al. $(2019,2020 b)$, with a domain length of $108 \mathrm{~km}$ in the $x$ and $y$ directions and $20 \mathrm{~km}$ in the vertical direction. Grid spacing was uniform in the horizontal at $250 \mathrm{~m}$ and uniform in the vertical at $100 \mathrm{~m}$. Top and bottom boundary conditions were free slip, and no radiation or surface-layer physics were used. Lateral boundary conditions (LBCs) were set to open radiative, following the method of Durran and Klemp (1983). The nonacoustic time step was set to $1.3 \mathrm{~s}$, simulations were run for $3 \mathrm{~h}$, and model data were output every $5 \mathrm{~min}$. Domain translation velocities were set to approximately center the primary updraft of interest within the domain for each simulation through a method of trial and error. Random temperature perturbations drawn from a uniform distribution with a maximum amplitude of $0.25 \mathrm{~K}$ were added to the initial conditions below $3 \mathrm{~km}$ to facilitate the development of turbulence.

The initial thermodynamic sounding in all simulations was a modified version of the analytic sounding from Weisman and Klemp (1982, hereinafter the WK82 sounding), with a boundary layer mixing ratio of $16 \mathrm{~g} \mathrm{~kg}^{-1}$ (Fig. 3a). Much like in Peters et al. (2019, $2020 \mathrm{~b}$ ), the relative humidity above $3 \mathrm{~km}$ was reduced (relative to the original WK82 sounding) to $45 \%$ to make the free tropospheric relative humidity consistent with that of typical central Great Plains severe weather environments. The CAPE for an air parcel with the average properties of the lowest $1 \mathrm{~km}$ of the atmosphere in this sounding was $2744 \mathrm{~J} \mathrm{~kg}^{-1}$, and the EIL is the lowest $2.2 \mathrm{~km}$ of the atmosphere (e.g., 
TABLE 1. Summary of the CM1 configuration.

\begin{tabular}{|c|c|c|}
\hline Attribute & Value/setting & Notes \\
\hline Fully compressible & Yes & \\
\hline Horizontal grid spacing & $250 \mathrm{~m}$ & \\
\hline Vertical grid spacing & $100 \mathrm{~m}$ & \\
\hline Nonacoustic time step & $1.3 \mathrm{~s}$ & \\
\hline Vertical coordinate & Height (m) & \\
\hline No. of $x$ and $y$ points & $1008 \times 1008$ & \\
\hline Vertical points & 180 & \\
\hline Top/bottom LBCs & Free slip & \\
\hline North/south LBCs & Open radiative & Durran and Klemp (1983) \\
\hline East/west LBCs & Open radiative & Durran and Klemp (1983) \\
\hline Convection initiation & $\begin{array}{l}\text { Warm bubble at domain center, with horizontal radius of } \\
5 \mathrm{~km} \text {, vertical radius of } 1.4 \mathrm{~km} \text {, and } \theta \text { perturbation of } 3 \mathrm{~K}\end{array}$ & \\
\hline Microphysics & Morrison & Morrison et al. (2009) \\
\hline Diffusion & Sixth order & \\
\hline Subgrid turbulence & TKE & \\
\hline Rayleigh dampening & Yes & \\
\hline Dissipative heating & Yes & \\
\hline Second- and sixth-order diffusion coef & $75-0.04$ & \\
\hline Longwave radiation & None & \\
\hline Shortwave radiation & None & \\
\hline Surface layer & None & \\
\hline Boundary layer physics & None & \\
\hline Cumulus parameterization & None & \\
\hline
\end{tabular}

CAPE $>100 \mathrm{~J} \mathrm{~kg}^{-1}$ and $\mathrm{CIN}>-250 \mathrm{~J} \mathrm{~kg}^{-1}$, as it is defined in T07; Fig. $3 \mathrm{~b}$ in this study). To track the origin of air parcels in order to address $\mathrm{H} 1$, a passive tracer was initialized below $2 \mathrm{~km}$. Convection was initiated by including a Gaussian shaped warm bubble at the horizontal center of the domain with a horizontal radius of $5 \mathrm{~km}$, a vertical radius of $1.4 \mathrm{~km}$, a vertical center height of $0.5 \mathrm{~km}$, and an amplitude of $3 \mathrm{~K}$.
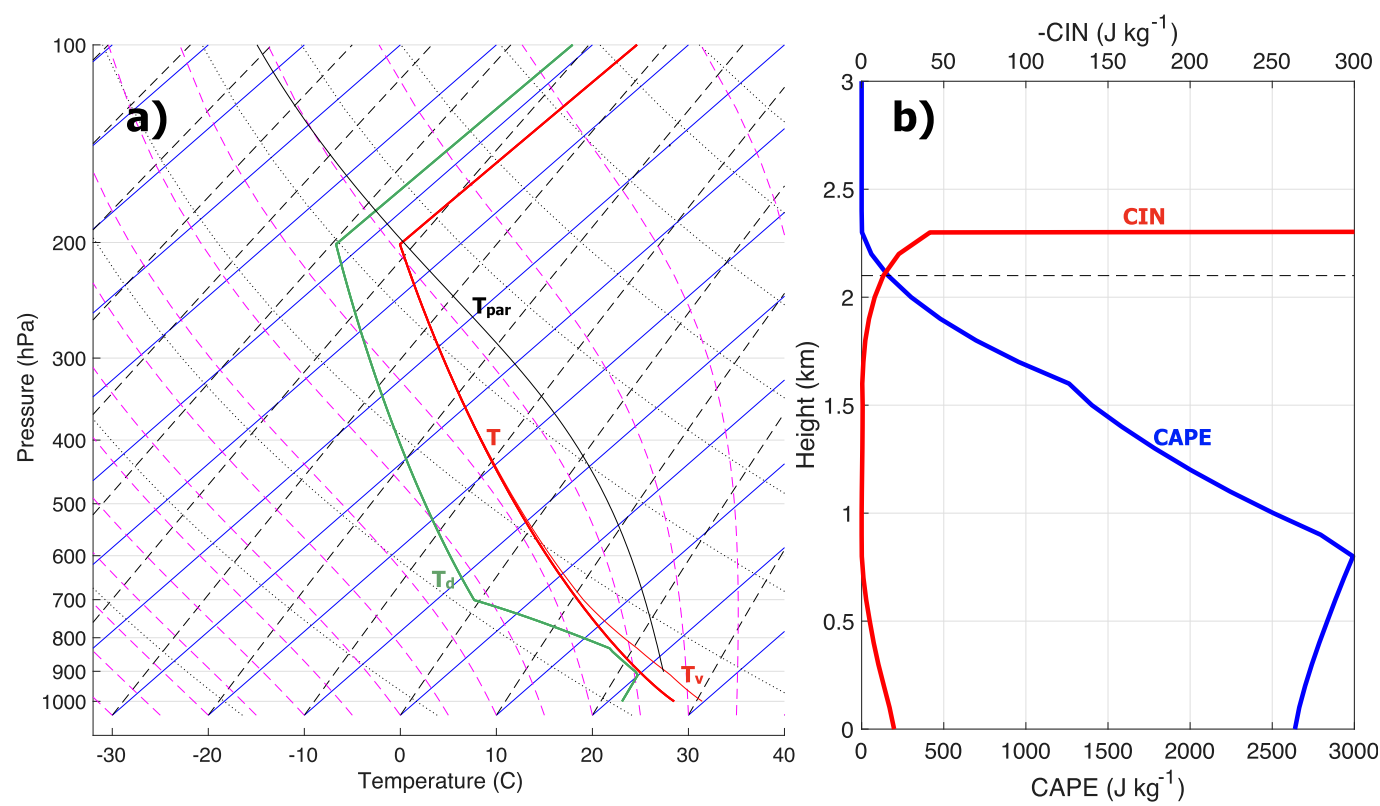

FIG. 3. (a) Skew $T-\log p$ diagram of the thermodynamic profile used in all simulations showing temperature $T$ (thick red line; C), virtual temperature $T_{v}$ (thin red line; C), dewpoint temperature $T_{d}$ (green line; $\mathrm{C}$ ), and the lifted parcel temperature $T_{\text {par }}$ (black line; C) for an air parcel with the average properties of the lowest $1 \mathrm{~km}$ of the atmosphere. (b) Vertical profiles of CAPE (blue line; $\mathrm{J} \mathrm{kg}^{-1}$ ) and - CIN (red line; $\mathrm{J} \mathrm{kg}^{-1}$ ) as a function of the initial height for a lifted parcel. The upper bound of the EIL is shown as a horizontal dashed line in (b). 

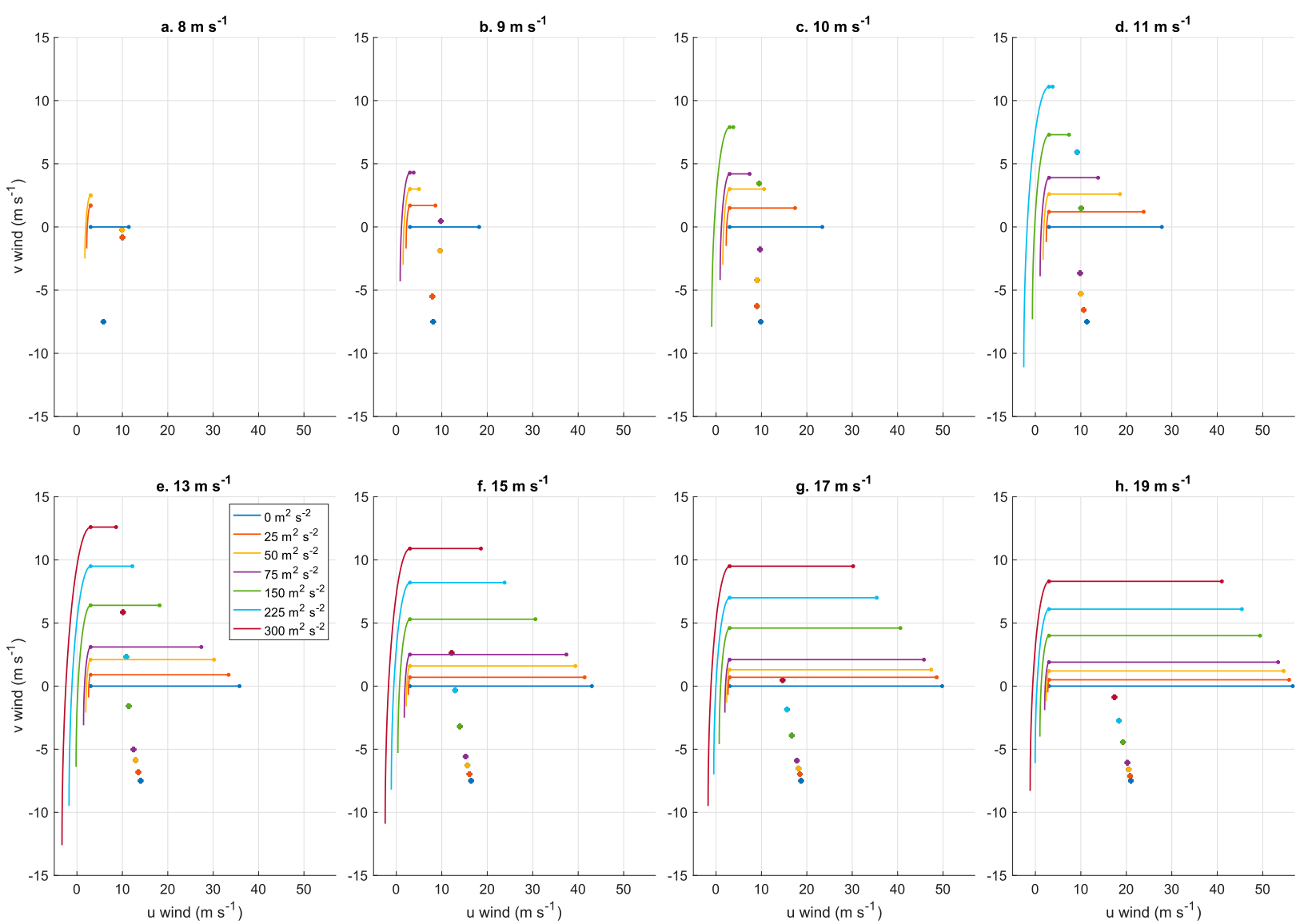

FIG. 4. Hodographs of the initial wind profiles used in this study, with $u$ wind $\left(\mathrm{m} \mathrm{s}^{-1}\right)$ on the $x$ axis and $v$ wind (m s${ }^{-1}$ ) on the $y$ axis. The first dot along each curve represents $1 \mathrm{~km}$, and the second dot along the curve represents $6 \mathrm{~km}$. Dots to the lower right of the curve are storm motion estimates using the Bunkers method. Bunkers SR flow magnitudes of 8, 9, 10, 11, 13, 15, 17, and $19 \mathrm{~m} \mathrm{~s}^{-1}$ are shown in (a)-(h), respectively. Bunkers SRH magnitudes are delimited by line colors in accordance with the legend in (e).

The numerical modeling experiments were designed to disentangle the separate contributions to storm properties by low-level SR flow and low-level $\omega_{s}$, and we accordingly varied SR flow and SRH independently of one another among simulations. This separation of SR flow and SRH was accomplished using the following wind profile formulation:

$$
\begin{aligned}
& u(z)=-\frac{c_{1}}{4} \cos \left(\frac{\pi}{2} \frac{z}{z_{s}}\right)+a_{1} \quad \text { and } \\
& v(z)=c_{1}\left[\sin \left(\frac{\pi}{2} \frac{z}{z_{s}}\right)-a_{2}\right]
\end{aligned}
$$

for $z \leq z_{s}$, where $z_{s}=2 \mathrm{~km}, a_{1}=3 \mathrm{~m} \mathrm{~s}^{-1}$, and $a_{2}=0.5$. Above $z_{s}$ and below $z_{t}=6 \mathrm{~km}$, the following formulas were used:

$$
u(z)=a_{1}+c_{2} \frac{z-z_{s}}{z_{t}-z_{s}} \quad \text { and }
$$

$$
v(z)=c_{1}\left(1-a_{2}\right),
$$

and above $6 \mathrm{~km}$ the wind was held constant. These formulae resulted in a modified "quarter-circle profile" (e.g., Rotunno and Klemp 1982), with clockwise turning of the shear vector below $2 \mathrm{~km}$ and uniform westerly shear between 2 and $6 \mathrm{~km}$. Among simulations, $0-2-\mathrm{km}$ SR flow and 0-2-km SRH [computed using the "ID method" of Bunkers et al. (2000)] were varied independently of one another by altering the parameters $c_{1}$ and $c_{2}$, which change the size of the hodograph in the 0 $2-\mathrm{km}$ layer and the 2-6-km layer, respectively. We focused on 0-2-km quantities because these spanned the approximate depth of the EIL for the WK82 profile used. Simulations featured 0-2-km mean SR flow magnitudes of 8 (Fig. 4a), 9 (Fig. 4b), 10 (Fig. 4c), 11 (Fig. 4d), 13 (Fig. 4e), 15 (Fig. 4f), 17 (Fig. 4g), and $19 \mathrm{~m} \mathrm{~s}^{-1}$ (Fig. 4h), and 0-2-km SRH magnitudes of 0, 25, $50,75,150,225$, and $300 \mathrm{~m}^{2} \mathrm{~s}^{-2}$. The 8 SR flow magnitudes and 7 SRH magnitudes resulted in 56 possible 
combinations of SR flow and SRH; however, certain combinations resulted in unrealistic profile shapes. For instance, for a quarter-circle profile to have $11 \mathrm{~m} \mathrm{~s}^{-1} 0$ 2-km SR flow and $300 \mathrm{~m}^{2} \mathrm{~s}^{-2}$ of $0-2-\mathrm{km} \mathrm{SRH}, c_{2}$ would have to be negative, resulting in an easterly shear above $2 \mathrm{~km}$ and an abrupt reversal in shear direction at $2 \mathrm{~km}$. Such SR flow and SRH combinations that resulted in negative $c_{2}$ values were omitted from the final set of simulations because their profile shapes were deemed unrealistic, resulting in 46 total simulations. ${ }^{2}$ Runs are hereinafter referred to by their Bunkers SRH and SR flow magnitudes (e.g., the SRH 300 SR 8 run). We note that simulated storm motions deviated slightly from the motion predicted by the Bunkers ID method; however, Bunkers estimated quantities and quantities computed from simulated storm motions were strongly correlated (see section 4a).

\section{b. Pressure perturbation analysis}

The connections between updraft vorticity, vertical accelerations, and updraft intensity occur by virtue of a storm's dynamic pressure perturbation structure. To understand this pressure perturbation structure, we decompose the anelastic pressure field into three components:

$$
\begin{aligned}
\nabla^{2} p_{B} & =\frac{\partial\left(\rho_{0} B\right)}{\partial z}, \quad \nabla^{2} p_{\mathrm{LD}}=-\rho_{0} \nabla w \cdot \frac{d \mathbf{V}_{0}}{d z}, \quad \text { and } \\
\nabla^{2} p_{\mathrm{NLD}} & =-\rho_{0}\left(e_{i, j}^{\prime} e_{i, j}^{\prime}-w^{2} \frac{d^{2} \ln \rho_{0}}{d z^{2}}+\frac{\boldsymbol{\omega}^{\prime} \cdot \boldsymbol{\omega}^{\prime}}{2}\right),
\end{aligned}
$$

where $\rho_{0}(z)$ is the density from the initial model sounding, $\mathbf{V}_{0}$ is the horizontal wind from the initial model sounding, $e_{i, j}^{\prime} \equiv\left[\left(\partial v_{i}^{\prime} / \partial x_{j}\right)+\left(\partial v_{j}^{\prime} / \partial x_{i}\right)\right]$ is the rateof-deformation tensor of the storm-modified wind $v_{i}^{\prime}$, $\boldsymbol{\omega}^{\prime}$ is the vector vorticity of the storm modified wind, $B \equiv-g\left(\rho^{\prime} / \rho_{0}\right)-g q_{i}$ is buoyancy (where $q_{i}$ is the mixing ratio of the $i$ th hydrometeor species), $p_{B}$ is referred to as "buoyancy pressure," $p_{\mathrm{NLD}}$ is referred to as "nonlinear dynamic pressure," and $p_{\mathrm{LD}}$ is referred to as "linear dynamic pressure." The individual terms in Eq. (6) were obtained from model output by solving for the right-hand-side terms, applying a horizontal 2D Fourier transform using the method of images to enforce zero-gradient lateral boundary conditions (e.g., Davies-Jones 2002), solving the resultant tridiagonal matrix equation in the vertical

\footnotetext{
${ }^{2}$ A set of simulations with a 500-m horizontal grid spacing and a lower CAPE value yielded nearly identical results to those presented in this article, suggesting that our results are insensitive to CAPE.
}

direction, and then inverting the 2D horizontal Fourier transform.

The distribution of $p_{B}$ is dependent on an updraft's thermodynamic and microphysical properties, and is not directly influenced by kinematics such as vorticity. The quantity $p_{\mathrm{LD}}$ is associated with the interaction between the ambient vertical wind shear and $w$ gradients along the flanks of an updraft (e.g., Rotunno and Klemp 1982). Finally, the quantity $p_{\mathrm{NLD}}$ is associated with regions of local storm-generated deformation and vorticity, which coincide with locally high and low $p_{\mathrm{NLD}}$, respectively. The low-level upward accelerations related to midlevel vorticity in supercells occur in response to the development of locally low $p_{\mathrm{NLD}}$ at midlevels that is collocated with the updraft's midlevel rotation (e.g., Rotunno and Klemp 1982). We will therefore investigate the influence of SRH on $p_{\mathrm{NLD}}$ in order to address H1. In contrast, the influences of SR flow on updraft intensity that were detailed in Peters et al. (2019) show up as differences in $B$ among updrafts, and we investigate these differences to address H1. Note that separate influences of vertical wind shear on updraft accelerations may arise through $p_{\mathrm{LD}}$, and we therefore investigate connections between the environmental wind to this term as well.

\section{c. Vertical accelerations along trajectories}

The pressure perturbation field is connected to vertical accelerations, and consequently $w$, via the following anelastic vertical momentum equation:

$$
\begin{aligned}
& \frac{D w}{D t}=B-\frac{1}{\rho_{0}} \frac{\partial p_{B}}{\partial z}-\frac{1}{\rho_{0}} \frac{\partial p_{\mathrm{LD}}}{\partial z}-\frac{1}{\rho_{0}} \frac{\partial p_{\mathrm{NLD}}}{\partial z}
\end{aligned}
$$

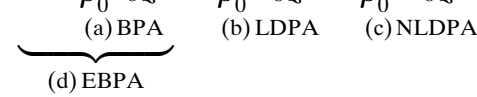

where term a is buoyancy pressure acceleration (BPA), term $b$ is linear dynamic pressure acceleration (LDPA), and term $c$ is nonlinear dynamic pressure acceleration (NLDPA). The sum of $B$ and BPA gives term $d$, the effective buoyancy pressure acceleration (EBPA; e.g., Davies-Jones 2002; Peters 2016). To compare these accelerations in the context of $w$ (i.e., updraft intensity), we followed the method of Peters et al. (2019) ${ }^{3}$ in defining the following quantities:

\footnotetext{
${ }^{3}$ Readers are referred to Peters et al. (2019, section $2 \mathrm{c}$ therein) for an explanation for why the quantities in Eq. (8) are used for comparisons among simulations rather than temporally integrated accelerations from Eq. (7).
} 


$$
\begin{aligned}
& w_{B} \equiv \sqrt{2 \int_{z=z_{0}}^{z=z_{t}} B d z}, \quad w_{\mathrm{EBPA}} \equiv \sqrt{2 \int_{z=z_{0}}^{z=z_{t}} \operatorname{EBPA} d z}, \quad w_{\mathrm{LD}} \equiv \sqrt{2 \int_{z=z_{0}}^{z=z_{t}} \operatorname{LDPA} d z}, \\
& w_{\mathrm{NLD}} \equiv \sqrt{2 \int_{z=z_{0}}^{z=z_{t}} \mathrm{NLDPA} d z}, \text { and } w_{\mathrm{NET}} \equiv \int_{t^{*}=t_{0}}^{t^{*}=t}(\mathrm{EBPA}+\mathrm{LDPA}+\mathrm{NLDPA}) d t^{*} \text {. }
\end{aligned}
$$

Each of the quantities in Eq. (8) (aside from $w_{\mathrm{NET}}$ ) represents the $w$ an air parcel would have at $z_{t}$ if the corresponding force(s) were acting alone. For instance $w_{B}$ represents the $w$ an air parcel would achieve if $B$ were the only vertically oriented force acting along the air parcel's path. Note that these quantities are undefined if the corresponding vertical integral of acceleration yields a negative value. If $\mathrm{H} 1$ were supported, we would expect a statistically insignificant correlation between $0-2-\mathrm{km} \mathrm{SRH}$ and $w_{\mathrm{NLD}}$, as well as a statistically significantly positive correlation between $0-2-\mathrm{km}$ SR flow and $w_{B}$ and consequently $w_{\text {NET }}$. The later correlation between SR flow and $w_{B}$ would be consistent with the findings of Peters et al. (2019), wherein we found that updrafts with larger low-level SR flow were wider, were less susceptible to entrainment-driven dilution, and were consequently more buoyant than updrafts with smaller low-level SR flow.

The individual contributions to Eqs. (7) and (8) were assessed along back trajectories (hereinafter simply "trajectories") that were released from within the updraft. To generate trajectories, restart files were written every 15 min during our initial model runs. To obtain trajectories with characteristics of the time-averaged updraft, we then reran 15 min of each simulation starting from the restart file at the beginning of the 15-min period with a time averaged updraft maximum $w$ that was closest to the 1-3-h average of the updraft maximum $w$. Model data were output every $5 \mathrm{~s}$ during these 15 -min restarts. Trajectories were released every $5 \mathrm{~s}$ during the restart period from the locations of the maxima in $w$ at $2 \mathrm{~km}$ (hereinafter " $2-\mathrm{km}$ trajectories"), $5 \mathrm{~km}$ (hereinafter "5-km trajectories"), and the grid points with the largest $w$ within the updraft (hereinafter "max trajectories").

The first backward time step was computed using a first-order Euler discretization of the time derivative. Subsequent time steps were integrated using a secondorder centered in-time "leapfrog" method. Trilinear interpolation was used to evaluate quantities along trajectories. Like in Peters et al. (2019), forward trajectories were also released from the locations of maximum $w$ since $w_{B}$ is often maximized above the height of maximum $w_{\text {NET }}$ along trajectories (e.g., Morrison and Peters 2018). Forward and backward trajectories were subsequently merged and all $w$ quantities were assessed as the maximum along the trajectory path in the case of the max trajectories. Assuming that the $w$ interpolated onto trajectories $\left(w_{\text {traj }}\right)$ represented the "true" $w$, we compared $w_{\text {traj }}$ with $w_{\text {NET }}$ ( $w$ obtained from integrating the vertical accelerations along the trajectory) to evaluate trajectory accuracy. Trajectories were only considered in further analysis if the ratio $r_{t}=\left[\max \left(w_{\mathrm{NET}}\right)-\right.$ $\left.\max \left(w_{\text {traj }}\right)\right] / \max \left(w_{\text {traj }}\right)$ was less than 0.1 .

\section{d. Tracking updrafts}

To track the primary right-moving supercell of interest, we use the updraft-tracking method of Peters et al. (2019). We found continuous regions of $0-4-\mathrm{km}$ mean $w>3 \mathrm{~m} \mathrm{~s}^{-1}$ and $0-4-\mathrm{km}$ mean $\bar{\zeta}>0 \mathrm{~s}^{-1}$. The updraft center point $\left(x_{s}, y_{s}\right)$ was defined as the vertical velocity weighted average of the locations within this continuous region. We defined the $3 \mathrm{D}$ extent of the updraft as continuous 2D slices of $w>3 \mathrm{~m} \mathrm{~s}^{-1}$ on each vertical level. We then found the index $k$ of the top of the 3D extent of the updraft, which corresponded to height $z_{k}$. We defined the remainder of the updraft above $z_{k}$ as a continuous $3 \mathrm{D}$ region of $w>3 \mathrm{~m} \mathrm{~s}^{-1}$ that touched any point that was part of the updraft at $z_{k}$. After this procedure, we used a subjective analysis of model fields to remove erroneous updraft points. Storm motion vectors $C_{x}$ and $C_{y}$ were defined by applying a Gaussian filter with a radius of influence of $10 \mathrm{~min}$ to the time series of $d x_{s} / d t$ and $d y_{s} / d t$ (these derivates were estimated using centered second-order finite differences in time). The results of our subsequent analysis were insensitive to changes to this procedure (such as changing the $w$ threshold for defining the updraft).

\section{Results from numerical experiments}

\section{a. General attributes of simulations}

All of the 46 simulations produced sustained convective activity throughout their $3 \mathrm{~h}$ integration periods. However, convection quickly became outflow dominant and evolved into squall-line-like structures in the simulations with $<10 \mathrm{~m} \mathrm{~s}^{-1}$ of $0-2-\mathrm{km}$ Bunkers SR flow. Furthermore, the convection in these runs with weaker 


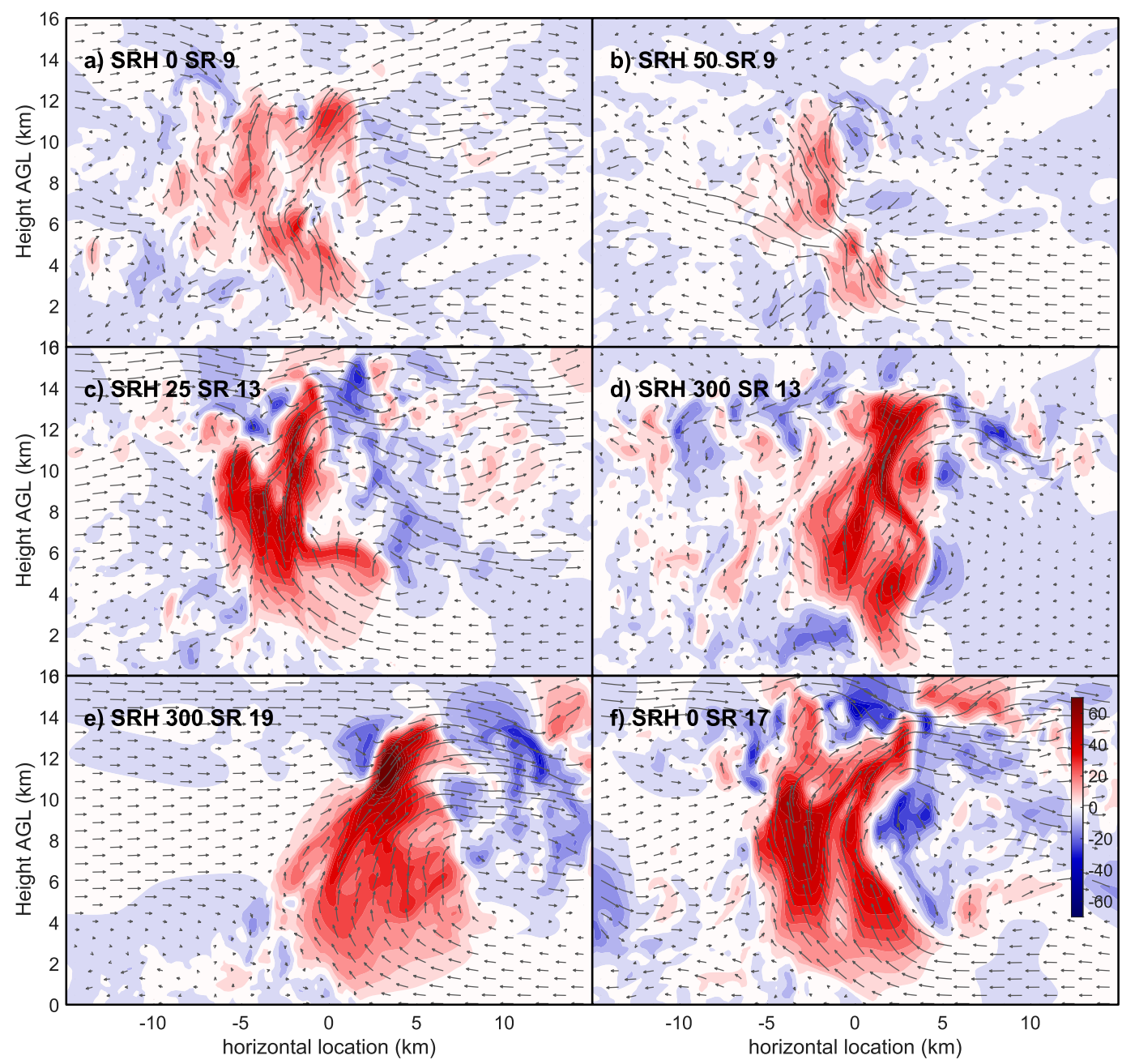

FIG. 5. Vertical cross sections through simulated updrafts at $145 \mathrm{~min}$, showing $w$ (shading; $\mathrm{m} \mathrm{s}^{-1}$ ) and crosssection-parallel streamlines (gray arrows) for the (a) SRH 0 SR 9, (b) SRH 50 SR 9, (c) SRH 25 SR 13, (d) SRH 300 SR 13, (e) SRH 300 SR 19, (f) and SRH 0 SR 17 runs.

SR flow was thermal-like in character, with the cloudy region in the simulations consisting of chains of transient discrete rising updraft pulses (e.g., Figs. 5a,b). This thermal-like behavior is ubiquitous among nonsupercellular convection (e.g., Bryan and Fritsch 2002; Sherwood et al. 2013; Romps and Charn 2015; Lebo and Morrison 2015; Hernandez-Deckers and Sherwood 2016; Morrison et al. 2020; Peters et al. 2020a). In contrast, runs with $>10 \mathrm{~m} \mathrm{~s}^{-1}$ of $0-2-\mathrm{km}$ Bunkers SR flow produced comparatively sustained plumelike updrafts, with continuous rising motion extending from the boundary layer into the upper troposphere (e.g., Figs. 5c-f). Furthermore, plumelike updraft structures in the runs with large SR flow were sustained for upward of $30 \mathrm{~min}$, and in some cases throughout the length of the simulation-especially in the case of the runs with the largest SR flow (e.g., Fig. 6). This result is consistent with Brandes et al. (1988), who also found that $10 \mathrm{~m} \mathrm{~s}^{-1}$ or greater of low-level SR flow as necessary to sustain a supercell updraft. In the runs with $\leq 10 \mathrm{~m} \mathrm{~s}^{-1}$ SR flow, the tracking procedure produced more erratic updraft tracks than in the runs with $>10 \mathrm{~m} \mathrm{~s}^{-1}$ SR flow because of the comparatively intermittent nature of updrafts in the environment with weak SR flow. Nevertheless, once the smoothing procedure had been applied to these tracks, our subjective analysis concluded that the smoothed track generally followed the region of most intense updrafts and radar reflectivity echoes, and statistics requiring storm motion such as SR flow and SRH were computed for several of these runs as well (all of the SR 8 runs, the SRH 50 SR 9, the SRH 75 SR 9, and the SRH 50 SR 10 were omitted from subsequent analysis because of poor performance of the tracking procedure). 


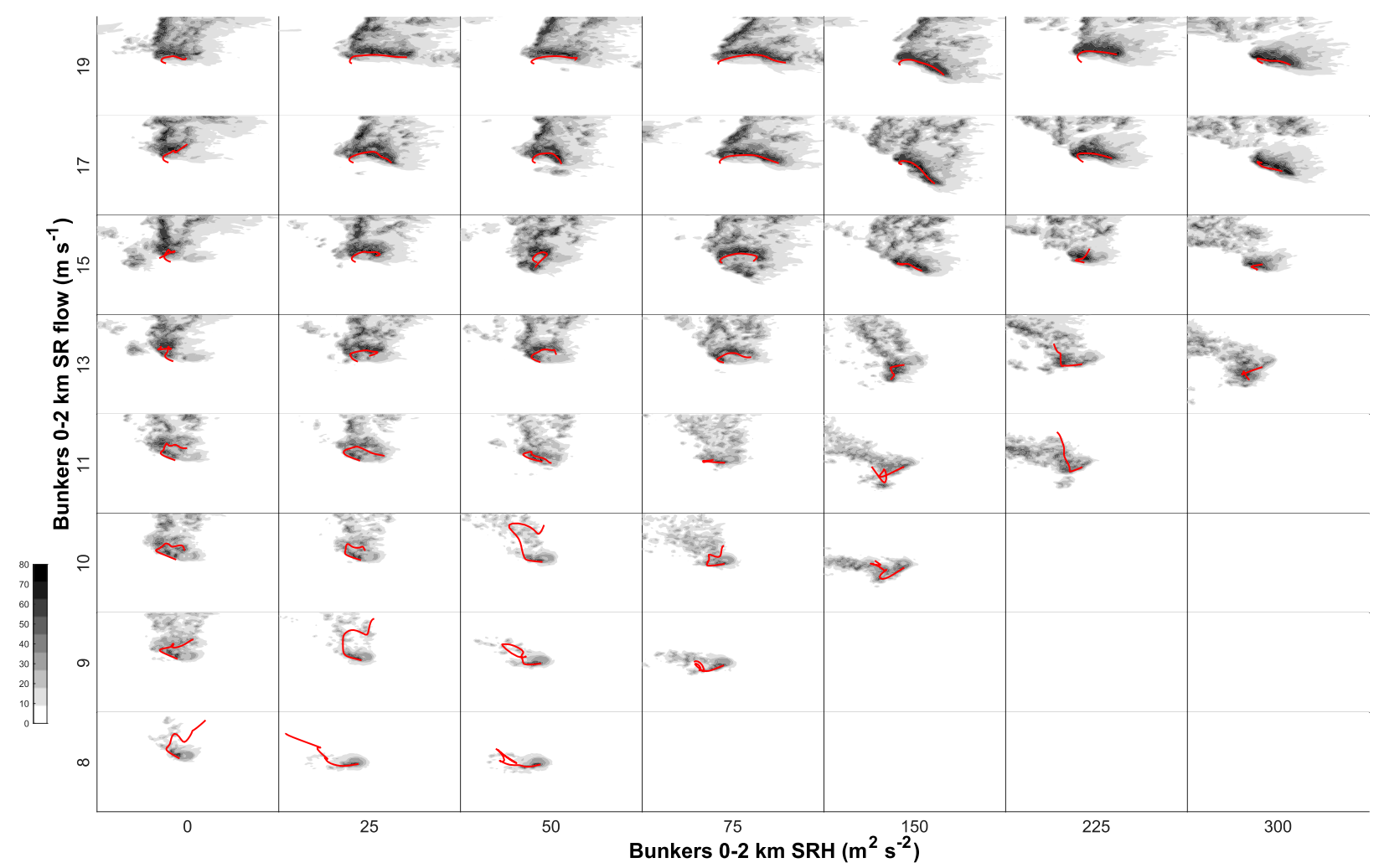

FIG. 6. Horizontal plots of the temporal maximum $w$ at $10 \mathrm{~km}$ AGL for each horizontal point within the domain (grayscale shading; $\mathrm{m} \mathrm{s}^{-1}$ ) and updraft tracks (red lines). The 0-2-km Bunkers SRH on the $x$ axis and Bunkers 0-2-km SR flow on the $y$ axis indicate which run is in each panel. Updraft tracks always near the center of each panel.

A subjective analysis of supercell composite radar reflectivity characteristics (Fig. 7) reveals features that are commonly associated with supercells among all runs with $>10 \mathrm{~m} \mathrm{~s}^{-1} 0-2-\mathrm{km}$ Bunkers SR flow, including the partitioning of precipitation into distinct rear-flank and forward flank regions, v-shaped signatures of large reflectivity within the forward flank precipitation, and hook-echo-like features. Hook-echo signatures were generally better defined for runs with larger SRH, and poorly defined in runs with little SRH. Runs with larger SRH also featured a more pronounced "horseshoe" shape to their updrafts, which is a common feature of "classic supercells," than those with less SRH. While the runs with low SRH did produce persistent updrafts, these runs also featured a larger amount of nonsupercellular "junk convection" along the eastern flank of their cold pools than the runs with large SRH (these differences are not explicitly shown in Fig. 7). In addition, the runs with the largest SRH also produced much less intense cold pools than the runs with the smallest SRH. The potential implications of these morphological differences are noted in section 5; however, the bulk of subsequent analysis focuses on the characteristics of the storm updrafts and how they relate to the environmental wind field, as these interactions are the focus of our hypotheses.

\section{b. Validation of experimental method}

Before diving into the analyses that quantitatively address our hypotheses, we performed several sanity checks to validate our experimental method. First, since simulated storm motions did deviate from Bunkers estimates for storm motions, we needed to determine whether we accomplished our goal of varying SRH and SR flow independently among simulations. Simulated SRH (Fig. 8a) and SR flow (Fig. 8b) were well correlated with the Bunkers estimates for these quantities (CC of 0.94 and 0.88 , respectively), and simulated SR flow and simulated SRH were uncorrelated (CC of 0.15 , not shown in Fig. 8), which is consistent with our experimental goal. We note that vertical variations in SR wind within the 0-2-km layer, in addition to the mean SR wind in this layer, may also influence storm properties. The standard deviation of SR flow in the 0-2-km layer was very small (e.g., standard deviations less than $1 \mathrm{~m} \mathrm{~s}^{-1}$ ) for most simulations indicating a uniform vertical profile of SR flow among most runs (Fig. 8b). An exception to this statement applies to the runs with 


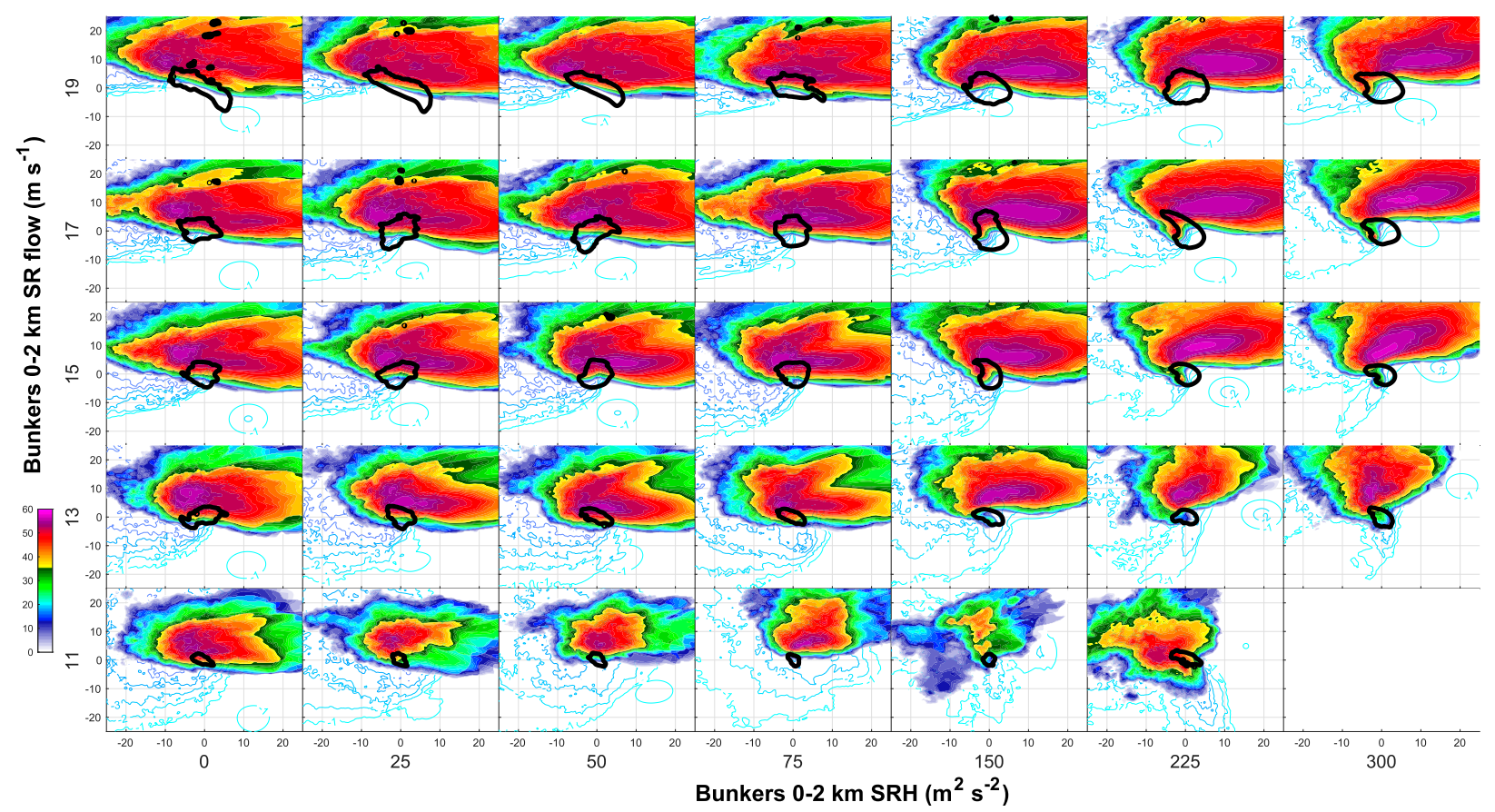

FIG. 7. The 1-3-h storm-centered composites of simulated radar reflectivity at $1 \mathrm{~km}$ AGL (shading; dBZ), surface temperature difference from the initial model profile (blue contours at intervals of $1 \mathrm{~K}$ ), and the $3 \mathrm{~m} \mathrm{~s}^{-1} 1-4-\mathrm{km} w$ contour (black). The figure layout follows that of Fig. 6. Only simulations that produced persistent supercell-like updrafts are shown.

smallest SR flow and largest SRH, which had much larger SR flow near the surface than near $2 \mathrm{~km}$.

Second, we must confirm that runs with large (low) SRH also had large (low) 0-2-km mean $\omega_{s}$, and likewise that $\omega_{s}$ was uncorrelated with SR flow. Figure 8c confirms that $\omega_{s}$ and SRH were well correlated (CC of 0.96), and $\omega_{s}$ and SR flow were uncorrelated. These results are again in line with our experimental goals of having SR flow and $\omega_{s}$ varied separately among simulations. We also note that, although deep-layer shear and low-level SR flow are strongly correlated (Fig. 8d; $C C=0.89$ ), we include measures of both SR flow and deep-layer shear in subsequent analysis because of the possibility of dynamical connections between deep-layer shear and updraft characteristics that do not relate to SR flow, such as vertical accelerations due to linear dynamic pressure perturbations (e.g., Rotunno and Klemp 1982).

\section{c. Bulk statistical analyses of simulations}

To begin our quantitative hypothesis evaluation, we compare the magnitudes of environmental SRH and SR flow with the following updraft characteristics:

1) vertical mass flux, which is defined as $M(z, t) \equiv \iint \rho w d A$, where $A$ is the updraft area at a given height and the horizontal integration was confined to the "updraft of interest" (updrafts with larger $M$ accomplish greater latent heat release, vertical water vapor flux, and vertical hydrometeor flux than updrafts with smaller $M$; consequently, precipitation production intrinsically relates to $M$ ),

2) the horizontal maximum of updraft $w$, which contributes to $M$, cloud microphysical properties, and associated societal threats related to heavy rainfall, hail, and cloud electrification,

3) the horizontal maximum of updraft vertical vorticity $\zeta$, which is a measure of updraft rotation and relates to the updraft minima in $p_{\mathrm{NLD}}$ (e.g., Rotunno and Klemp 1982),

4) updraft rotation speed, which is defined as $v_{\text {rot }} \equiv l^{-1}$ $\iint \zeta d A=C / l$, where $C$ is circulation and $l$ is the perimeter length of an updraft at a given height $\left(v_{\text {rot }}\right.$ is related to the average $\zeta$ within an updraft), and

5) updraft width, measured as effective radius $\left[R_{\text {eff }} \equiv\right.$ $(A / \pi)^{1 / 2}$ ] [updraft width strongly modulates $M$, entrainment (e.g., Peters et al. 2019), and consequently buoyancy, vertical accelerations, and $w$; wider updrafts will also have larger downward-oriented BPA, which may partially compensate for increasing buoyancy].

Unless explicitly stated otherwise in figures or text, all measures of SRH and SR flow use simulated storm motions from the updraft-tracking procedure described in section 2 .

The magnitudes of $M$ were weakly correlated with SRH (Fig. 9a; $0.42<\mathrm{CC}<0.45$ ) but were uncorrelated 


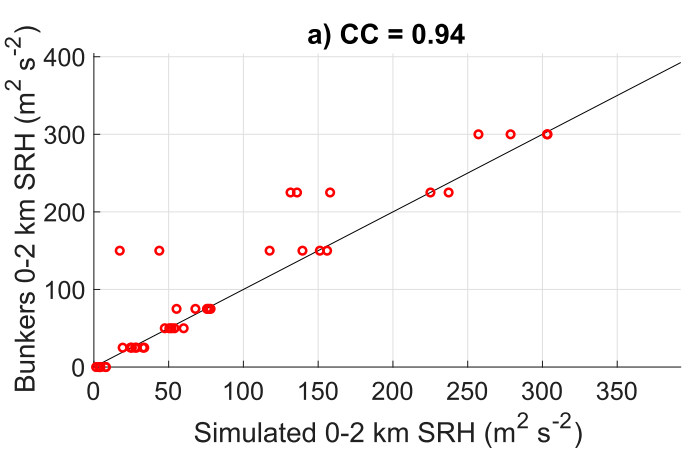

c) $\mathrm{CC}=0.96$

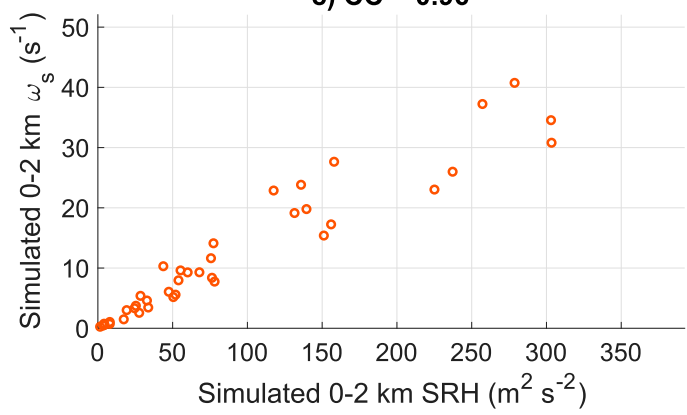

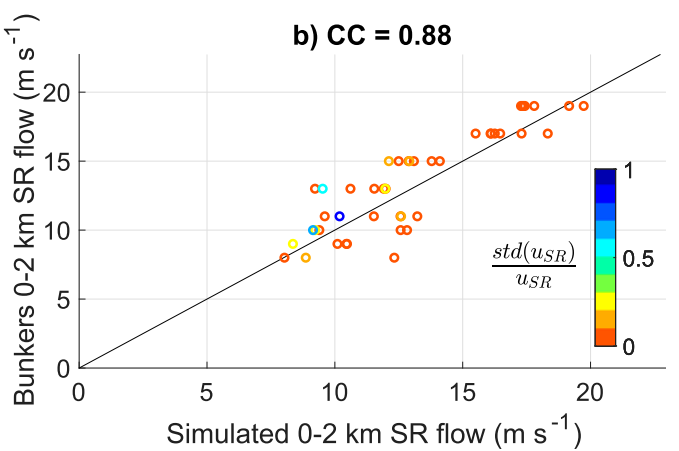

d) $\mathrm{CC}=\mathbf{0 . 8 9}$

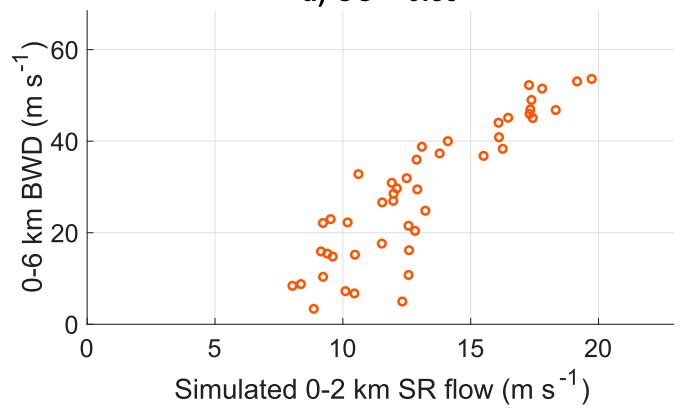

FIG. 8. (a) Scatterplot of the Bunkers 0-2-km SRH ( $y$ axis; $\mathrm{m}^{2} \mathrm{~s}^{-2}$ ) vs the 0-2-km SRH computed with the simulated storm motion ( $x$ axis; $\mathrm{m}^{2} \mathrm{~s}^{-2}$ ). (b) Scatterplot of the Bunkers 0-2-km SR flow ( $y$ axis; $\mathrm{m} \mathrm{s}^{-1}$ ) vs the 0-2-km SR flow computed with the simulated storm motion $\left(u_{\mathrm{SR}} ; x\right.$ axis; $\left.\mathrm{m} \mathrm{s}^{-1}\right)$. One-to-one lines are shown in black in (a) and (b). The colors of the dots in (b) indicate the ratio of the standard deviation of $0-2-\mathrm{km} u_{\mathrm{SR}}$ in the vertical direction to the magnitude of $u_{\mathrm{SR}}$, and corresponding values for this ratio are shown in the color bar. (c) Scatterplot of simulated 0-2-km SRH $\left(x\right.$ axis; $\mathrm{m}^{2} \mathrm{~s}^{-2}$ ) vs simulated $0-2-\mathrm{km} \omega_{s}\left(y\right.$ axis; $\left.\mathrm{s}^{-1}\right)$. (d) Scatterplot of simulated SR flow $\left(x\right.$ axis; $\left.\mathrm{m} \mathrm{s}^{-1}\right)$ vs the $0-6-\mathrm{km} \mathrm{BWD}\left(y\right.$ axis; $\left.\mathrm{m} \mathrm{s}^{-1}\right)$. Values of CC are shown in the panel titles.

with $\omega_{s}$ at all levels (Fig. 9b). This result suggests that a factor related to SRH other than $\omega_{s}$ is responsible for the weak correlations between SRH and $M$, such as the shape of the low-level wind profile and how it interacts with convective outflow. In contrast, $M$ was strongly correlated with SR flow and the 0-6-km BWD at all levels (e.g., $\mathrm{CC}>0.86$; Figs. 9c,d). The relationship between low-level SR flow and $M$ is intuitive, in that large (small) low-level SR flow equates to large (small) horizontal mass flux into the updraft base (Warren et al. 2017; Peters et al. 2019), and mass continuity dictates that $M$ must directly correlate with an updraft's lowlevel inflow (see Peters et al. 2019). Since the correlations between $M$ and both SR flow and the $0-6-\mathrm{km}$ BWD were identical, the connection between the $M$ and the 0-6-km BWD was likely a result of the strong physical connection between the 0-6-km BWD and SR flow (i.e., faster storm motion when deep-layer shear is stronger).

SRH and $\omega_{s}$ were moderately correlated with $w$ at 2 and $5 \mathrm{~km}(0.49<\mathrm{CC}<0.65$; Figs. 10a,b). The SR flow and $0-6-\mathrm{km}$ BWDs, on the other hand, were weakly and moderately correlated with $w$ at $2 \mathrm{~km}(0.42<\mathrm{CC}<$ $0.48)$ and $5 \mathrm{~km}(0.52<\mathrm{CC}<0.61$; Figs. $10 \mathrm{c}, \mathrm{d})$. This result suggests that $\omega_{s}$ does indeed contribute to low- to midlevel updraft velocities. Both SRH and $\omega_{s}$ were weakly correlated with $w$ above $5 \mathrm{~km}$ (Figs. 10e-f), whereas both SR flow and the 0-6-km BWD were moderately and strongly correlated with $w$ at $8 \mathrm{~km}$ and the height of maximum $w$, respectively $(0.63<\mathrm{CC}<$ 0.85 ; Figs. $10 \mathrm{~g}, \mathrm{~h})$. This result suggests that the connections between $\omega_{s}$ and $w$ are confined to low to midlevels, while SR flow exerts a greater influence at mid- to upper levels.

Perhaps surprising is that SRH and $\omega_{s}$ were both uncorrelated with maximum updraft $\zeta$ at both 2 and $5 \mathrm{~km}$ (Figs. 11a,b). This seemingly contradicts the results of Droegemeier et al. (1993), who found strong correlations between SRH and updraft $\zeta$ maxima (e.g., $\mathrm{CC}>$ 0.9). However, those authors did not attempt to separate the SR flow and $\omega_{s}$ parts of SRH within their experimental design, and the strong correlations they found may have been a consequence of the strong correlation between SRH and SR flow. Indeed they found an equally strong correlation between $0-3-\mathrm{km}$ SR flow and updraft $\zeta$ maxima, and correlations between $\zeta$ at $2 \mathrm{~km}$ and both the SR flow and 0-6-km BWD were weak to moderate $(0.36<\mathrm{CC}<0.56$; Figs. $11 \mathrm{c}, \mathrm{d})$. This result 
a)

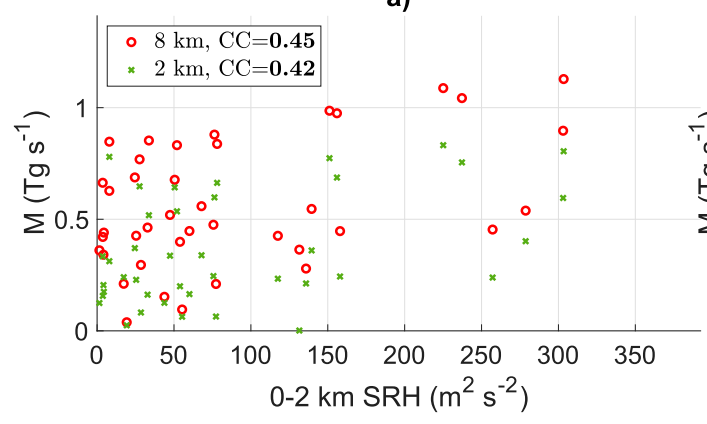

c)

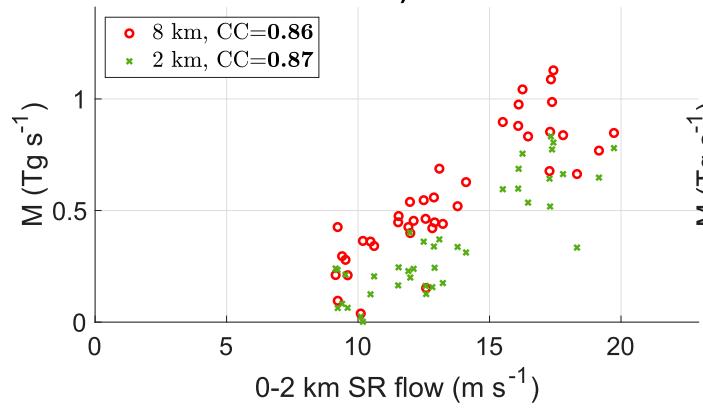

b)
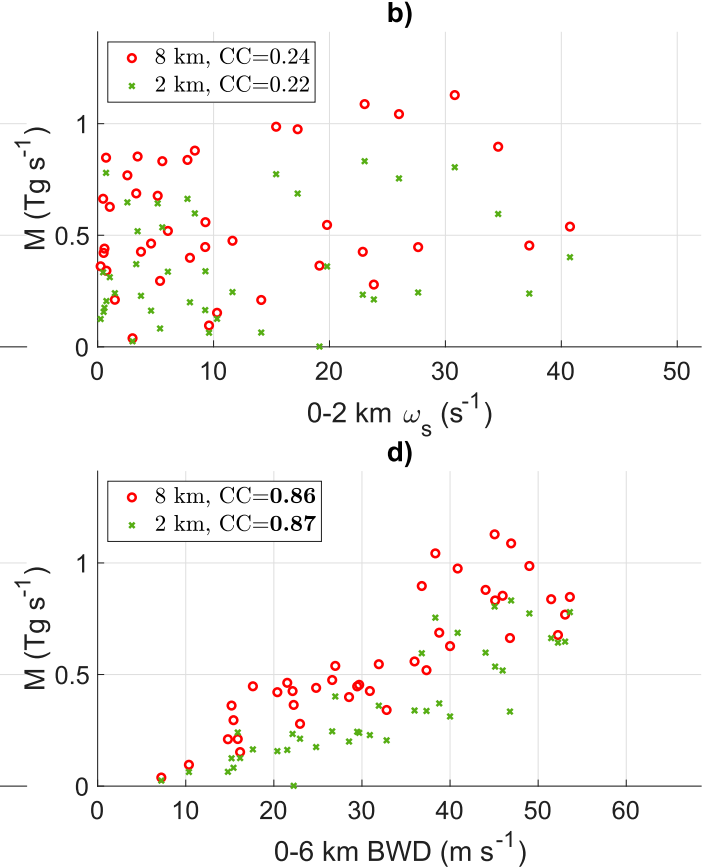

FIG. 9. Scatterplots of 2-km (green symbols) and 8-km (red symbols) 1-3-h average vertical mass flux $M$ ( $y$ axes; $\mathrm{Tg} \mathrm{s}^{-1}$ ) within tracked updrafts, as a function of (a) 0-2-km SRH $\left(\mathrm{m}^{2} \mathrm{~s}^{-2}\right)$, (b) $0-2-\mathrm{km} \omega_{s}\left(\mathrm{~s}^{-1}\right)$, (c) 0-2-km SR flow $\left(\mathrm{m} \mathrm{s}^{-1}\right)$, and $(\mathrm{d})$ the $0-6-\mathrm{km} \mathrm{BWD}\left(\mathrm{m} \mathrm{s}^{-1}\right)$. CCs for quantities are shown in the legends of each panel, with boldface text indicating statistical significance.

suggests that the maximum vorticity in updrafts at low levels is primarily generated by storm baroclinicity, and a combination of baroclinicity and tilting of ambient horizontal vorticity contribute to the maximum vertical vorticity aloft. It is also possible that the local maxima in $\zeta$ in the present simulations occurred on scales that were smaller than what was resolvable in the simulations of Droegemeier et al. (1993), who used a horizontal grid spacing of $1 \mathrm{~km}$.

Net updraft rotation at $2 \mathrm{~km}$ was strongly correlated with both SRH and $\omega_{s}(0.91<\mathrm{CC}<0.93$; Figs. 12a,b), and uncorrelated with SR flow (Figs. 12c,d). This is consistent with the results of previous authors (e.g., Rotunno and Klemp 1982; Davies-Jones 1984; Droegemeier et al. 1993; Davies-Jones 2002) who have shown that $\zeta$ and $w$ become increasingly correlated as low-level SRH becomes large, which implies that the updraft averaged $\zeta$ and consequently $v_{\text {rot }}$ also become large with large SRH. Physically speaking, this implies that storms ingesting large SRH should have more pronounced low-level mesocyclones than those ingesting smaller lowlevel SRH. Interestingly, correlations between SRH and $\omega_{s}$, and $v_{\text {rot }}$ become weaker at $5 \mathrm{~km}$ and comparable to the correlations between $v_{\text {rot }}$ and both the SR flow and 0-6-km BWD (Figs. 12a-d), which again implicates that both the stretching of baroclinically generated vorticity and the tilting of ambient midlevel vorticity contribute to updraft rotation aloft. The reason for such large differences between the correlations of SRH with level maximum $\zeta$, and the correlations of SRH with net updraft rotation at low levels suggests that tilting of environmental streamwise vorticity is more important for the development of updraft averaged rotation, whereas baroclinic processes were more important for the development of local maxima in $\zeta$ at low levels.

SRH and $\omega_{s}$ were weakly correlated and uncorrelated with updraft width, respectively (Figs. 13a,b). In contrast, SR flow and 0-6-km BWDs were both strongly correlated with updraft width $(\mathrm{CC}>0.85$; Figs. $13 \mathrm{c}, \mathrm{d})$. This result bolsters the findings of Peters et al. (2019, $2020 \mathrm{~b})$ in that it excludes $\omega_{s}$ as a primary influencing factor on updraft width.

\section{d. Evaluation of vertical accelerations along trajectories}

The analysis shown in the last section suggests that the overall influence of SRH and $\omega_{s}$ on updraft characteristics is limited to an enhancement of low-level updraft $w$, along with a strong influence on the net updraft rotation at low levels. In this section, we explore the dynamics responsible for these relationships using our trajectory analysis to explain the relative influences of 

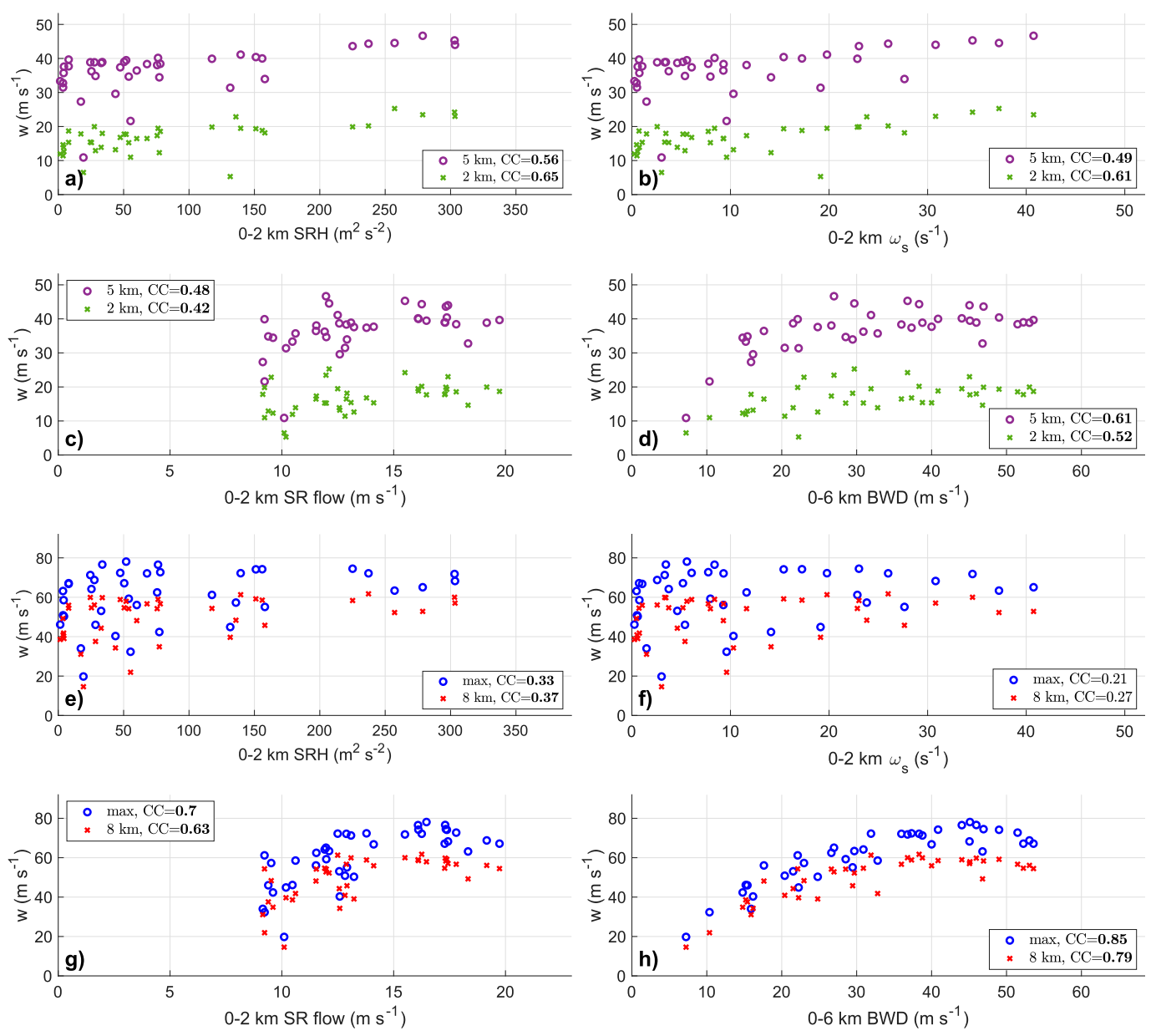

FIG. 10. Scatterplots of 1-3-h averages of the maximum updraft $w\left(\mathrm{~m} \mathrm{~s}^{-1}\right)$ at 2 (green symbols) and 5 (purple symbols) $\mathrm{km}$ as a function of (a) 0-2-km SRH $\left(\mathrm{m}^{2} \mathrm{~s}^{-2}\right)$, (b) 0-2-km $\omega_{s}\left(\mathrm{~s}^{-1}\right),(\mathrm{c})$ 0-2-km SR flow $\left(\mathrm{m} \mathrm{s}^{-1}\right)$, and (d) the 0-6-km BWD ( $\left.\mathrm{m} \mathrm{s}^{-1}\right)$. (e)-(h) As in (a)-(d), but for the maximum updraft $w\left(\mathrm{~m} \mathrm{~s}^{-1}\right)$ at $8 \mathrm{~km}$ (red symbols) and the overall updraft maximum $w$ (blue symbols). CCs for quantities are shown in the legends of each panel, with boldface text indicating statistical significance.

SRH, SR flow, and 0-6-km BWDs on updraft accelerations. In particular, we determine whether the lowlevel updraft enhancement in the environments with large SRH and $\omega_{s}$ was a result of an enhancement of lowlevel DPA in these environments. Then we disentangle the force balances responsible for controlling the middle- to upper-tropospheric updraft $w$ to determine why the DPA contributions from SRH and $\omega_{s}$ did not seem to influence $w$ at these levels. The total number of trajectories (percentages of all trajectories) that passed the accuracy test described in section $3 \mathrm{c}$ for origins at 2 and $5 \mathrm{~km}$ and the level of maximum updraft were 3117,2706 , and 339 , respectively ( $86 \%, 74 \%$ and $93 \%$, respectively). The quantities $B$, NLDPA, LDPA, BPA, EBPA, $w_{B}$, $w_{\mathrm{EBPA}}, w_{\mathrm{LD}}, w_{\mathrm{NLD}}$, and $w_{\mathrm{NET}}$ were all computed along trajectories and compared among runs. For each run, we compared the average of each of the aforementioned quantities over all usable trajectories to the SRH, SR flow, and 0-6-km BWD.

Correlations between SRH and $w_{\mathrm{LD}}$ were generally small in magnitude (Fig. 14a), which stands to reason given that $w_{\mathrm{LD}}$ is dynamically dependent on the overall shear magnitude rather than SRH. In contrast, moderate $(\mathrm{CC}=0.62)$ and strong $(\mathrm{CC}=0.79)$ correlations were present between SRH and $w_{\mathrm{NLD}}$ for 2- and 5-km trajectories, respectively (Fig. 14b). These correlations vanished for the max trajectories confirming that any "dynamic boost" afforded by storms from ingesting large low-level SRH and $\omega_{s}$ was confined to low levels. Correlations between SRH and $w_{B}$ (Fig. 14d) and $w_{\text {EBPA }}$ (Fig. 14e) for all trajectories were generally weak or insignificant, though a moderate correlation was present between $w_{\text {EBPA }}$ at $2 \mathrm{~km}$ and SRH (this is potentially a result of stronger low-level negative buoyancy associated 
a)

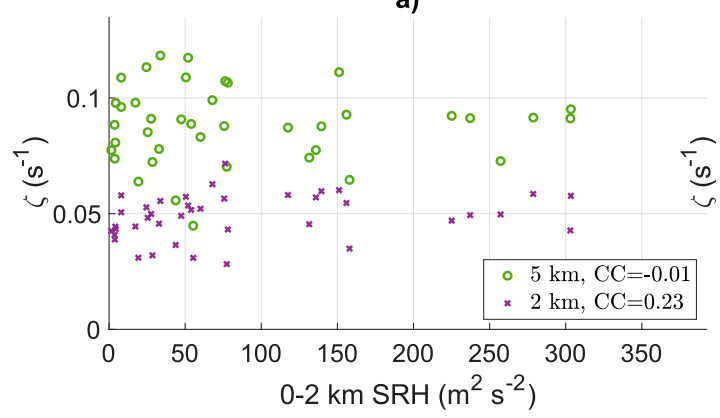

c)

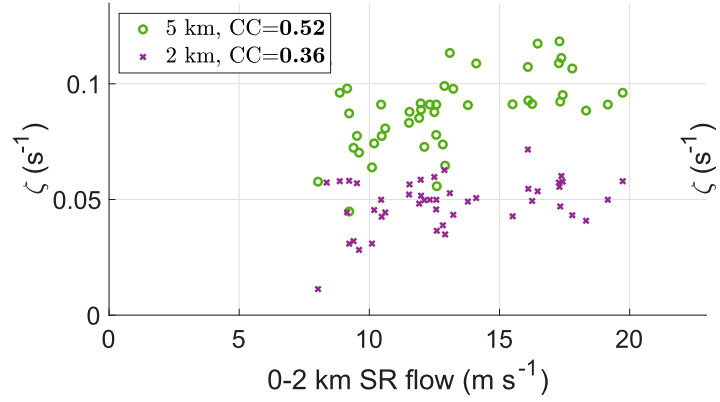

b)

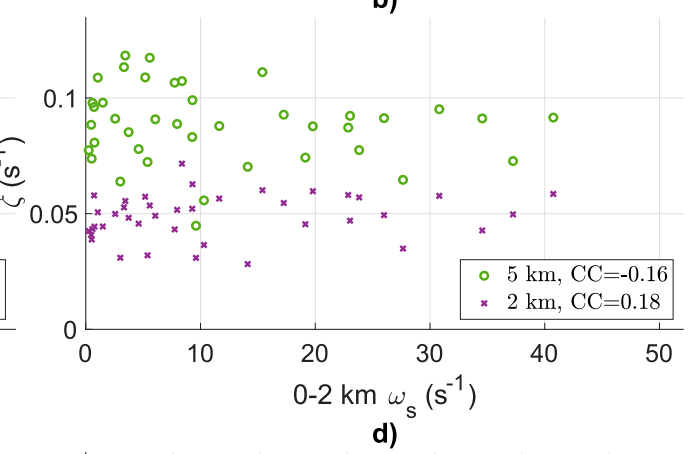

FIG. 11. As in Fig. 10, but showing 1-3-h averages of the maximum updraft vertical vorticity $\zeta\left(\mathrm{s}^{-1}\right)$ at 2 (purple symbols) and 5 (green symbols) $\mathrm{km}$.

with adiabatic lift occurring with the strong low-level dynamic lift that accompanies large SRH). Correlations between SRH and $w_{\text {NET }}$ were more-or-less consistent with the results for $w_{\mathrm{NLD}}$ (Fig. 14f). This result supports
$\mathrm{H} 1$, in that large $\omega_{s}$ gives low-level updrafts a boost via NLDPA over updrafts in environments with small $\omega_{s}$ but has little dynamical influence on updrafts in the middle to upper troposphere. a)

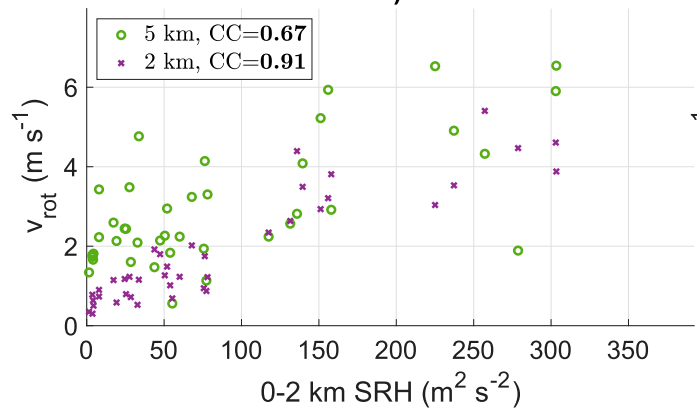

c)

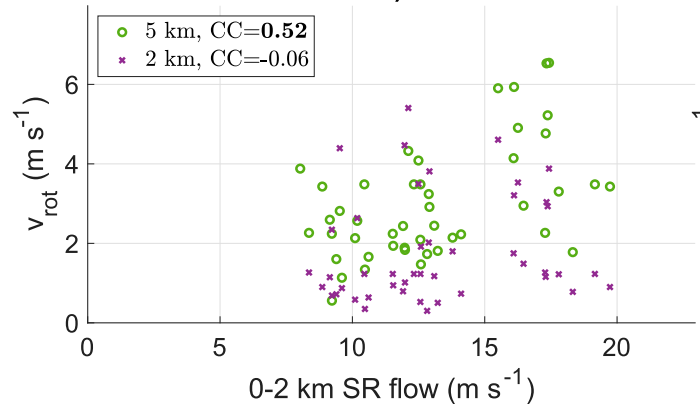

b)
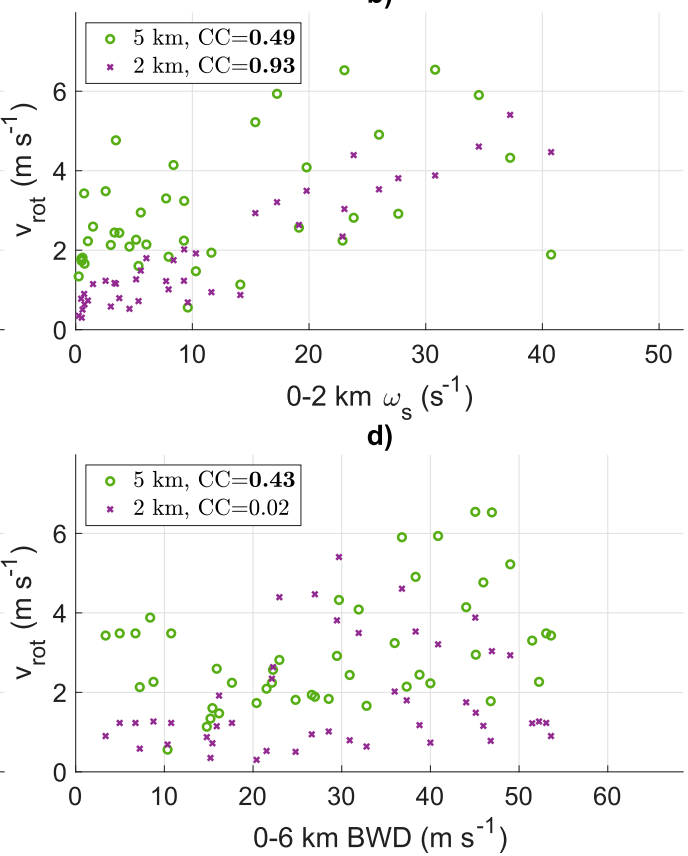

FIG. 12. As in Fig. 10, but showing 1-3-h averages of $v_{\text {rot }}\left(\mathrm{m} \mathrm{s}^{-1}\right)$ at 2 (green symbols) and 5 (purple symbols) km. 
a)

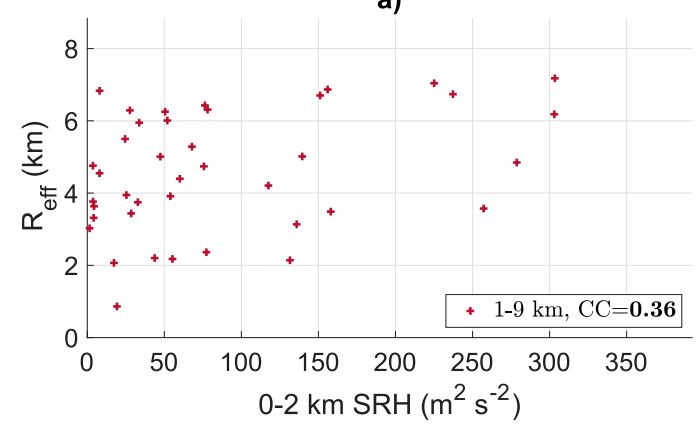

c)

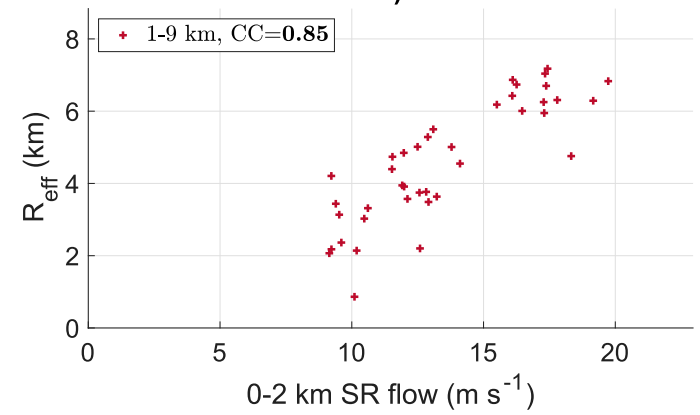

b)
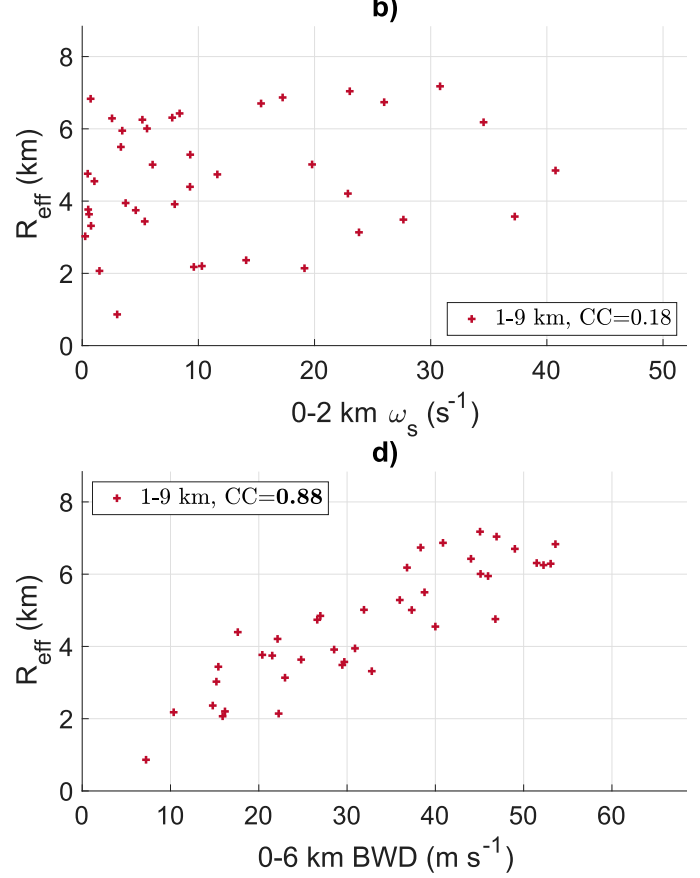

FIG. 13. As in Fig. 10, but showing 1-3-h averages of $R_{\text {eff }}(\mathrm{km}$; dark red symbols).

Correlations between SR flow, and $w_{\mathrm{LD}}$ and $w_{\mathrm{NLD}}$, were weak for the 2- and 5-km trajectories, and moderate for max trajectories (Figs. 15a-f). Furthermore, $w_{\mathrm{LD}}$ (Fig. 15a), $w_{\mathrm{NLD}}$ (Fig. 15b), and $w_{\mathrm{LD}}+w_{\mathrm{NLD}}$ (Fig. 15c) were more strongly correlated with SR flow for the max trajectories than with SRH (Figs. 14a-c). Moderate-to-strong correlations (e.g., CC of 0.5-0.8) between SR flow and both $w_{B}$ (Fig. 15d) and $w_{\text {EBPA }}$ (Fig. 15e) along the max trajectories echo the results of Peters et al. (2019), who showed that wider updrafts in environments with stronger SR flow allowed for larger updraft buoyancy. Note that downward BPA generally increases as updrafts widen (e.g., Morrison 2016; Peters 2016); however, this effect was apparently small for the range of updraft widths considered here in that the trends between SR flow and $w_{B}$ appear very similar to those between SR flow and $w_{\text {EBPA }}$. Interestingly, correlations between SR flow, and $w_{B}$ (Fig. 15d) and $w_{\text {EBPA }}$ (Fig. 15e) were weak or even significantly negative for 2 - and $5-\mathrm{km}$ trajectories. Reasons for this result are unclear, but may reflect an increasing participation of cold-pool air parcels in the runs where SR flow was large and cold pools were most intense.

Correlations between 0-6-km BWDs and $w_{\mathrm{LD}}$ were considerably stronger at all levels than those between SR flow and $w_{\text {LD }}$ (cf. Fig. 15a and Fig. 16a). This is a potential result of the so-called updraft-in-shear effect (Rotunno and Klemp 1982), wherein the interaction between the updraft and the ambient vertical wind shear produces locally high $p_{\mathrm{LD}}$ upshear of the updraft and locally low $p_{\mathrm{LD}}$ downshear. Air parcels approaching below the low $p_{\mathrm{LD}}$ would have experienced upward LDPA, and the magnitude of this LDPA should scale with the vertical wind shear magnitude. Correlations between $0-6-\mathrm{km}$ BWDs and $w_{\mathrm{NLD}}$ were also stronger than those between SR flow and $w_{\mathrm{NLD}}$ along the $5-\mathrm{km}$ and max trajectories (Fig. 16b; and the sum of $w_{\mathrm{LD}}$ and $w_{\mathrm{NLD}}$ also follows this pattern; Fig. 16c). One possible explanation for this connection is that the tilting of ambient horizontal vorticity related to the shear above the EIL generates vertical vorticity maxima and related $p_{\mathrm{NLD}}$ minima in the updraft, and that parcels entering the updraft below these $p_{\mathrm{NLD}}$ minima would presumably experience net upward accelerations.

However, there are also more complicating potential influences of 0-6-km shear on LDPA and NLDPA. Both of these variables are dependent on $w$. Furthermore, 0 $6-\mathrm{km}$ shear tends to occur with larger $w_{B}$ and $w_{\text {EBPA }}$ because of the strong correlation between 0-6- $\mathrm{km}$ shear, SR flow, updraft width, and entrainment (e.g., Peters et al. 2019). LDPA and NLDPA may therefore be stronger when 0-6-km shear is stronger simply because $w_{B}$ and $w_{\text {EBPA }}$ (Figs. 16d,e; and by association $w_{\mathrm{NET}}$; Fig. 16f) tend to be stronger when $0-6-\mathrm{km}$ shear is stronger. While it is admittedly difficult to completely disentangle the direct kinematic impacts of $0-6-\mathrm{km}$ shear on LDPA and NLDPA from the indirect effects 
a)

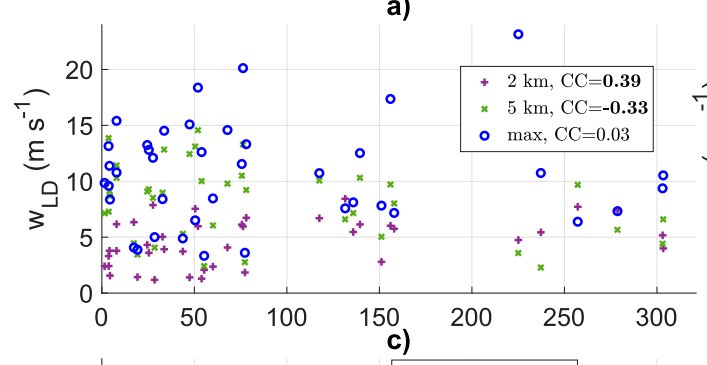

b)

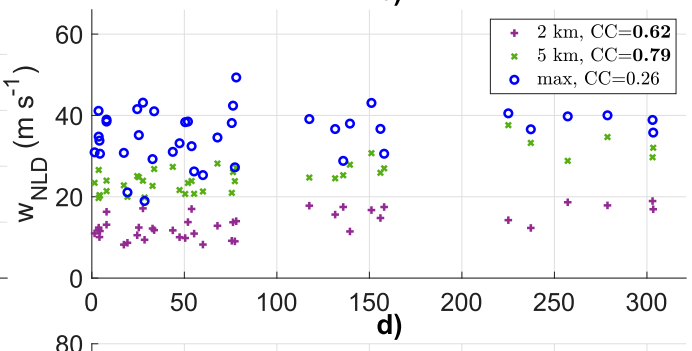

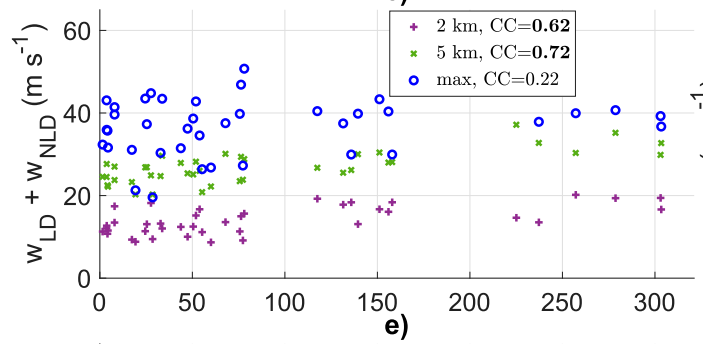
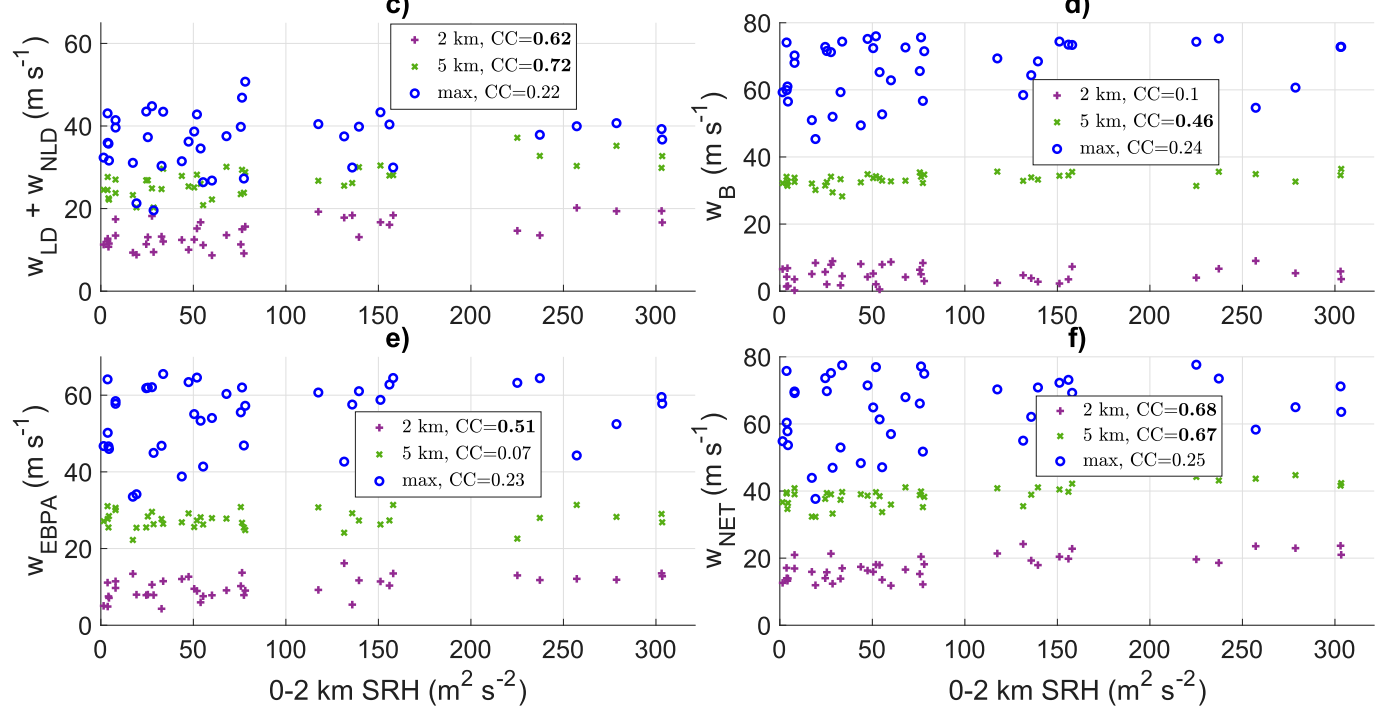

FIG. 14. Scatterplots of trajectory averaged (a) $w_{\mathrm{LD}}$, (b) $w_{\mathrm{NLD}}$, (c) $w_{\mathrm{LD}}+w_{\mathrm{NLD}}$, (d) $w_{B}$, (e) $w_{\mathrm{EBPA}}$, and (f) $w_{\mathrm{NET}}$ for trajectories released from the 2-km maxima in $w$ (purple symbols; evaluated at $2 \mathrm{~km}$ ), trajectories released at the 5 -km maxima in $w$ (green symbols; evaluated at $5 \mathrm{~km}$ ), and trajectories released at the updraft maximum $w$ (blue symbols; taken as the maximum over the entire trajectory). All $w$ quantities are plotted as a function of 0-2-km SRH $\left(\mathrm{m}^{2} \mathrm{~s}^{-2}\right)$ computed using the simulated storm motion. CCs for quantities are shown in the legends of each panel, with boldface text indicating statistical significance.

of 0-6-km shear on these variables via the thermodynamic arguments described in Peters et al. (2019), we attempt to show evidence for the former connection in the next subsection.

\section{e. Structural aspects of simulated updrafts that explain our statistical results}

To provide context and explanation for the statistical results of the previous subsection, we compare the structure of the SRH 0 SR 17 supercell (i.e., a supercell with strong low-level SR flow, but no $\omega_{s}$ within its EIL) to the SRH 300 SR 19 supercell (i.e., a supercell with comparable SR flow, but large $\omega_{s}$ within its EIL) at $145 \mathrm{~min}$. Horizontal cross sections at $3 \mathrm{~km}$ show substantially differing flow structures (Figs. 17a,b). The SRH 0 run featured a uniform horizontal flow direction within its updraft with little $\zeta$ (Fig. 17a), whereas the SRH 300 run featured a $180^{\circ}$ counterclockwise-turning flow signature within its updraft that is characteristic of low-level supercell mesocyclones (e.g., Dahl 2017;
Peters et al. 2020b) and substantial cyclonic $\zeta$ within its updraft (Fig. 17b). At $6 \mathrm{~km}$, however, the differences between the two updrafts become comparatively subtle (Figs. 17c,d). Both runs featured a broad maximum in cyclonic $\zeta$ and minimum in $p_{\mathrm{NLD}}$ along the southern flank of the updraft. The flow gradients associated with this vorticity appear to be more related to horizontal shear vorticity, rather than curvature vorticity, and pronounced $360^{\circ}$ rotation is markedly absent in both updrafts. The major difference between the two updrafts is the presence of greater cyclonic vorticity near the updraft center in the SRH 300 run (Fig. 17d), when compared with the SRH 0 run (Fig. 17c). There are also apparent differences in updraft width, but these differences are unlikely to be systematically a result of differences in $\mathrm{SRH}$, considering that no correlation was found between SRH and updraft width in Fig. 13. An analysis of the concentration of EIL tracer at $6 \mathrm{~km}$ reveals largest concentrations of nearly 1 in the updraft center, and comparatively weaker concentrations of 
a)
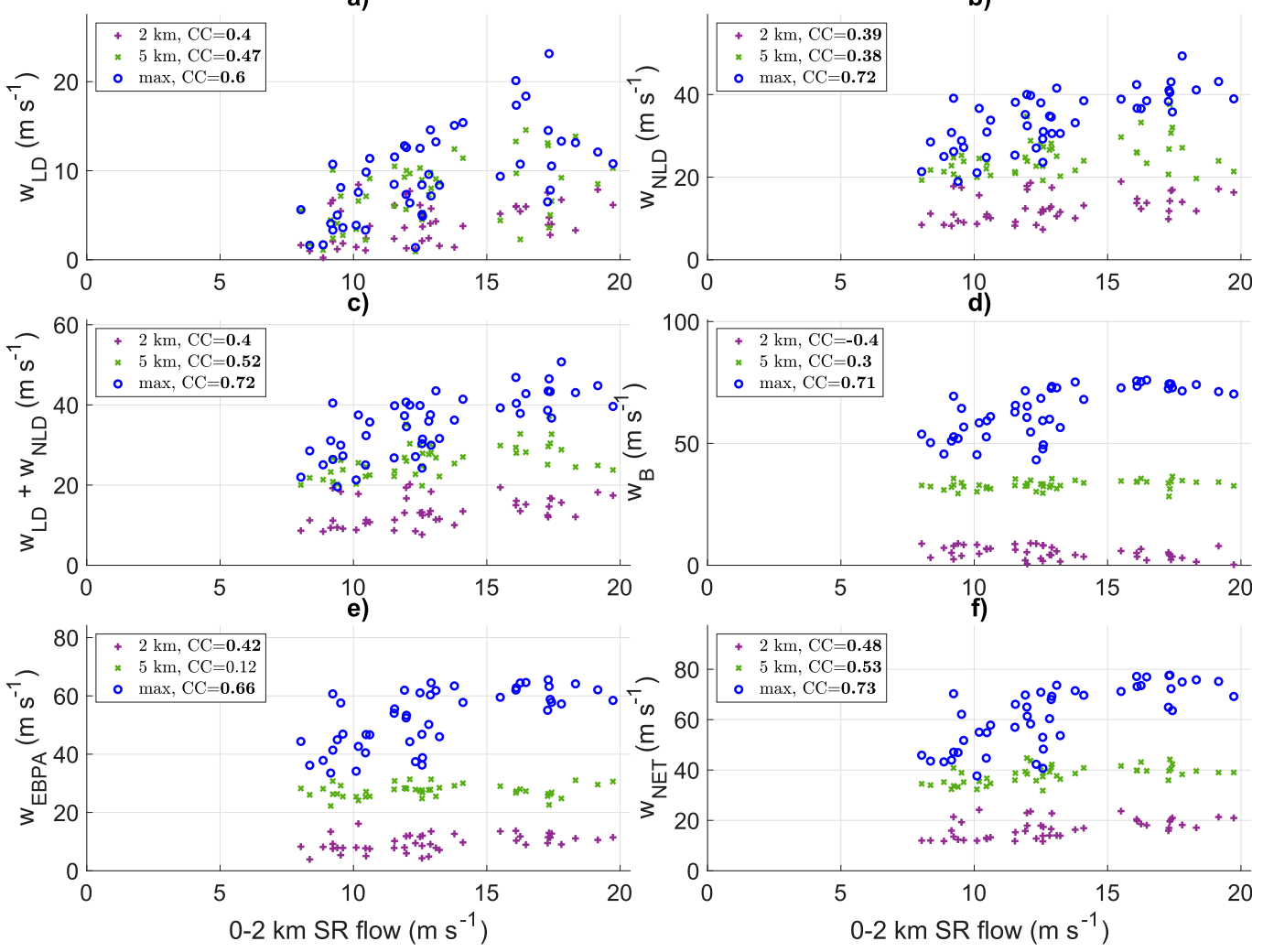

FIG. 15. As in Fig. 14, but with quantities plotted as a function of the 0-2-km mean SR flow computed using the simulated storm motion $\left(\mathrm{m} \mathrm{s}^{-1}\right)$.

b)
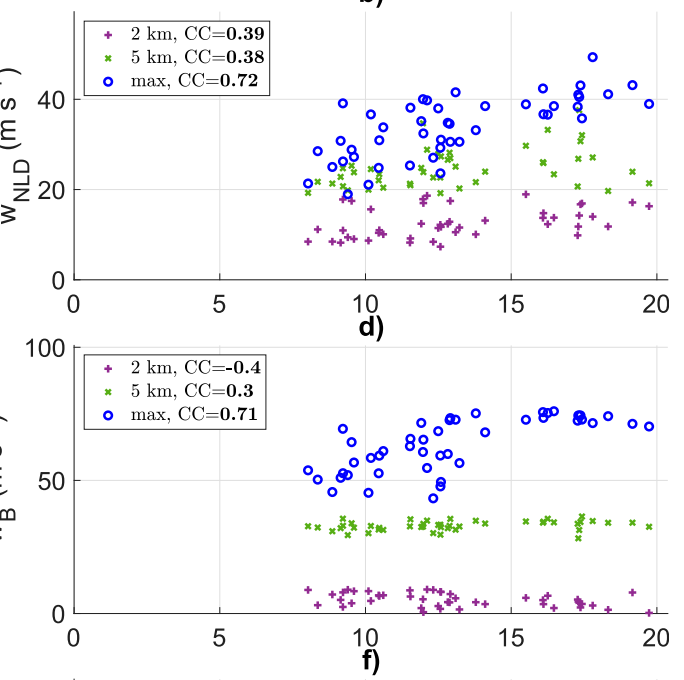
. . 
a)
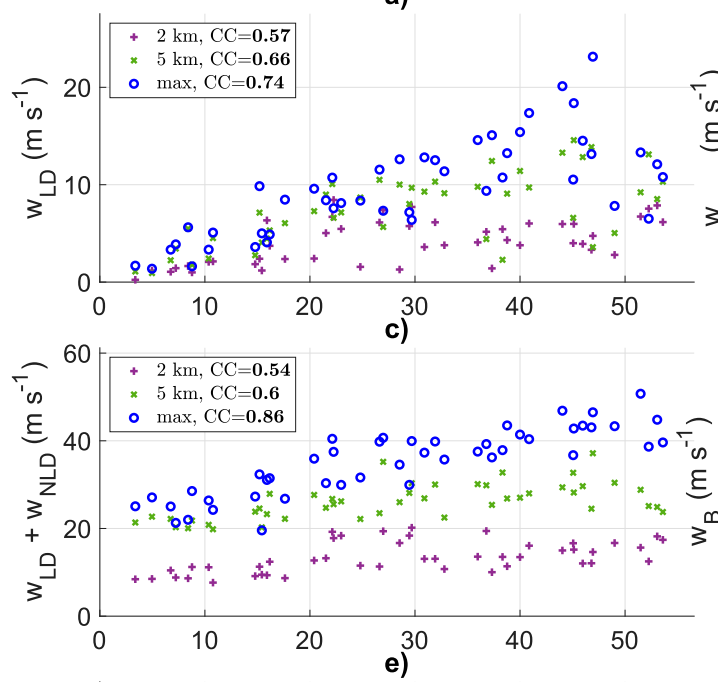

b)
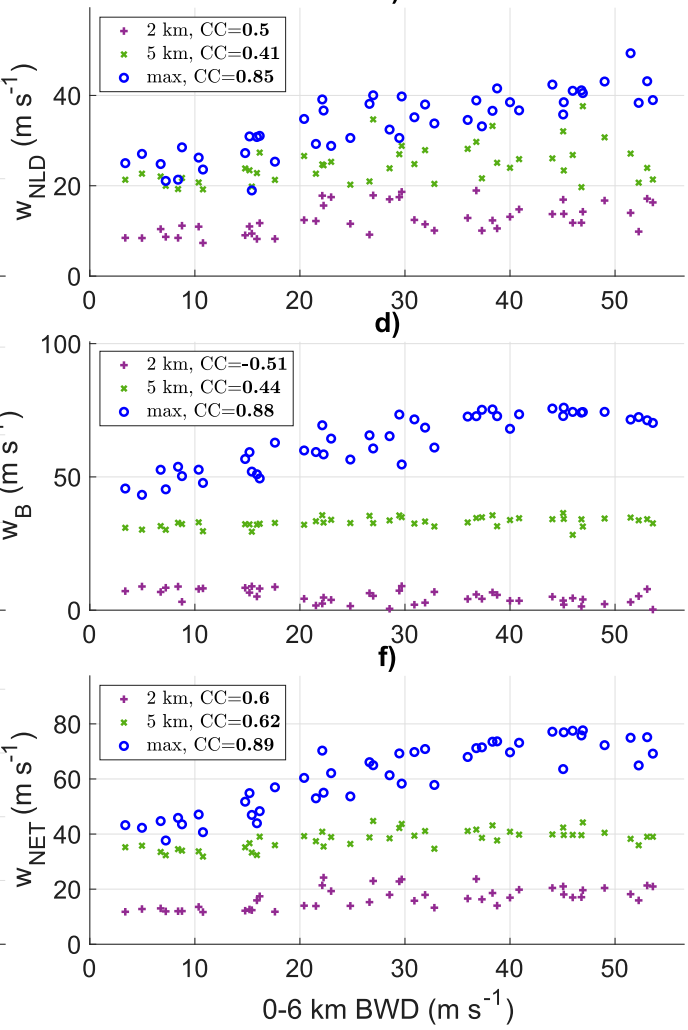

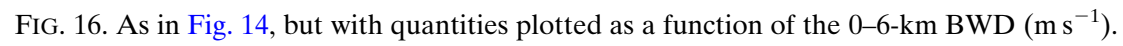

origins of a large percentage of air within the updraft $\zeta$ maxima, along with the presence of comparable $\zeta$ in the SRH 0 run to that in the SRH 300 run, suggest that the tilting of midlevel environmental vorticity plays a substantial role in the development of these local maxima in $\zeta$. In the case of the runs with large SRH, the addition of large $\zeta$ at lower levels in the updraft core simply extended this $p_{\mathrm{NLD}}$ feature downward, but was not necessarily responsible for its origin.

The assertions of the previous paragraph are further supported by an analysis of the percentage of EIL tracer within the 80th-percentile largest $\zeta$ located within the updraft at a given time, ${ }^{4}$ as evaluated between 4 and $8 \mathrm{~km}$, and averaged between 1 and $3 \mathrm{~h}$. Larger (smaller) percentage values of this quantity indicate a larger (smaller) participation in the generation of $\zeta$ maxima by air originating from the EIL (Fig. 19a). Percentages generally ranged from $35 \%$ to $51 \%$; however, most updrafts had concentrations ranging from $30 \%$ to $45 \%$, demonstrating that (in general) approximately $55 \%-70 \%$

\footnotetext{
${ }^{4}$ Visual analyses of these regions indicated that they coincided with the southern flank of the updraft and the region of locally low $p_{\text {NLD }}$.
}

of the air coinciding with the midlevel vorticity maxima had originated from above the EIL. This supports the idea that the tilting of horizontal vorticity above the EIL substantially contributes to updrafts' $p_{\text {NLD }}$ minima at midlevels. The percentage of vorticity within these midlevel maxima that was streamwise $\left(H_{\text {rel }} \equiv \omega_{s} /|\boldsymbol{\omega}|\right.$, where $\boldsymbol{\omega}$ is the $3 \mathrm{D}$ vorticity vector) ranged from $32 \%$ to $65 \%$, further suggesting a substantial role of crosswise vorticity in generating these midlevel $p_{\mathrm{NLD}}$ minima (Fig. 19b). This is unsurprising given that the tilting of crosswise vorticity is essential to the splitting and initial propagation of storms within straight-shaped hodograph environments (e.g., Rotunno and Klemp 1982), and would lead to the observed $\zeta$ maximum (minimum) on the southern (northern) flanks of the updraft given the mid- to upper-level hodograph shape. Obviously, a variety of percentages of crosswise and streamwise vorticity are likely to be present above the EIL in real supercell events; however, these results suggest that streamwise vorticity is not necessary aloft for the development of substantial dynamic pressure perturbations and the associated NLDPA. Furthermore, research and forecasting would benefit from a focus on total horizontal vorticity in a supercell's environment in addition to $\omega_{s}$ encompassed 


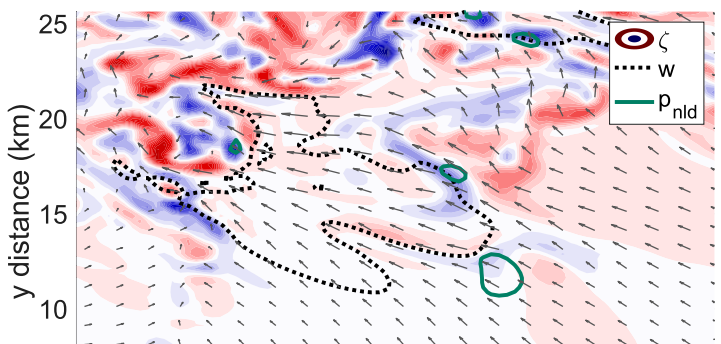

a) SRH 0 SR $17,3 \mathrm{~km}$

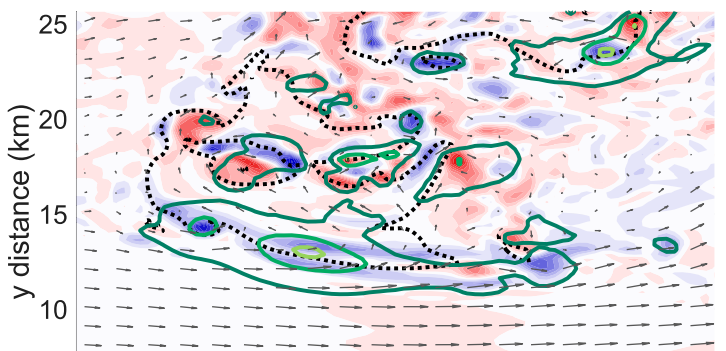

c) SRH 0 SR 17, $6 \mathrm{~km}$

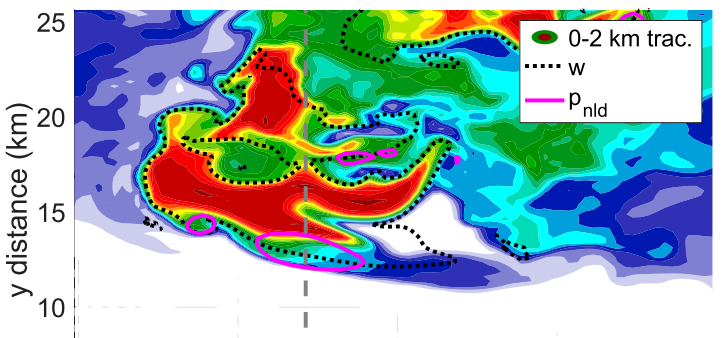

e) SRH 0 SR 17, $6 \mathrm{~km}$
$-10$

$\mathrm{x}$ distance $(\mathrm{km})$

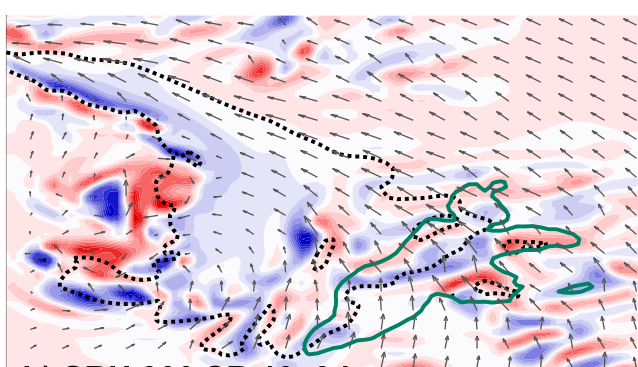

b) SRH 300 SR 19, $3 \mathrm{~km}$

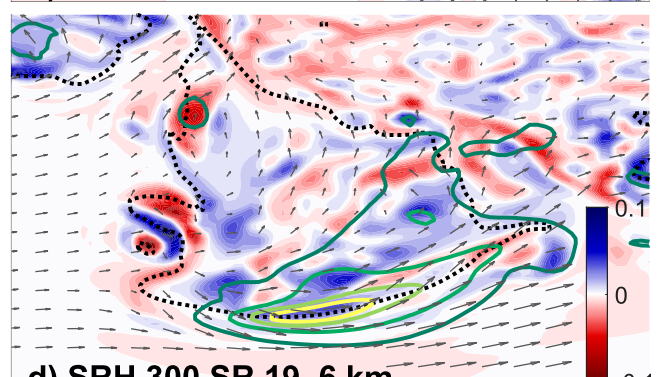

d) SRH 300 SR 19, 6 km二二三二二

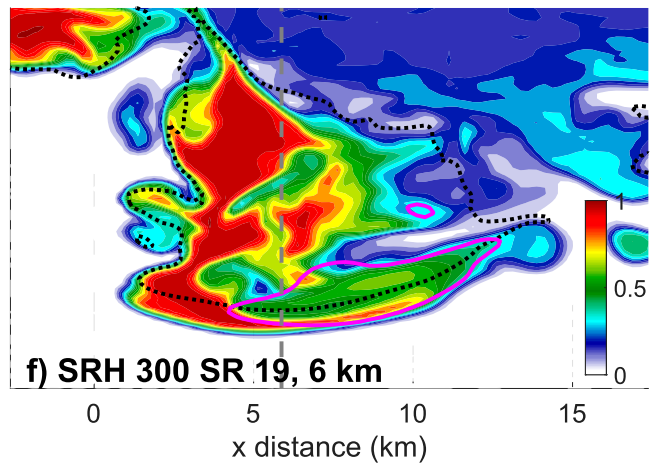

FIG. 17. (top),(middle) Horizontal slices through simulated updrafts showing vertical vorticity $\zeta$ (shading; $\mathrm{s}^{-1}$ ), $p_{\mathrm{NLD}}<0$ (green contours descending at intervals of $-2 \mathrm{hPa}$, and starting at $-1 \mathrm{hPa}$, with lighter greens indicating more negative values), $w$ at 10 [in (a) and (b)] and 20 [in (c) and (d)] $\mathrm{m} \mathrm{s}^{-1}$ (black contours), and storm-relative wind speeds and directions (gray arrows). (bottom) Concentration of the tracer initialized between 0 and $2 \mathrm{~km}$ (shading), $w$ at $20 \mathrm{~m} \mathrm{~s}^{-1}$ (black contours), the $-2-\mathrm{hPa} p_{\mathrm{NLD}}$ contour (magenta lines), and the path of cross sections shown below in Fig. 18 (gray dashed lines). Panels are valid at $145 \mathrm{~min}$ and show the SRH 0 SR 17 simulation at (a) 3, (c) 6, and (e) $6 \mathrm{~km}$ and the SRH 300 SR 19 simulation at (b) 3, (d) 6 , and (f) $6 \mathrm{~km}$.

with SRH, echoing the findings of Weisman and Rotunno (2000).

\section{Summary, conclusions, and discussion}

Although it is well known that EIL (particularly near ground) $\omega_{s}$ substantially influences tornadogenesis, fewer concrete connections have been made between EIL $\omega_{s}$ and the properties of supercell updrafts above the lowest few kilometers of the atmosphere. This is because SRH is commonly used to measure $\omega_{s}$, and SRH is strongly dependent on SR flow, which also influences updraft properties. The purpose of this article was therefore to isolate the separate roles of SR flow and $\omega_{s}$ through an analysis of proximity soundings and simulations wherein
SR flow and SRH were varied independently of one another. Our conclusions are as follows:

- Proximity sounding analysis suggests that $\omega_{s}$ need not be present within a storm's EIL for supercell formation. Rather, deep-layer shear and SR flow metrics are the most skillful predictors for supercellular storm mode.

- Important updraft properties such as $M$, width, maximum $\zeta$, and overall updraft maximum $w$ are primarily determined by SR flow and deep-layer shear, rather than $\omega_{s}$. This result suggests that many of the practical societal impacts of supercells such as rainfall, hail production, and electrification may be more sensitive to SR flow than $\omega_{s}$, and that the forecast and diagnostic 

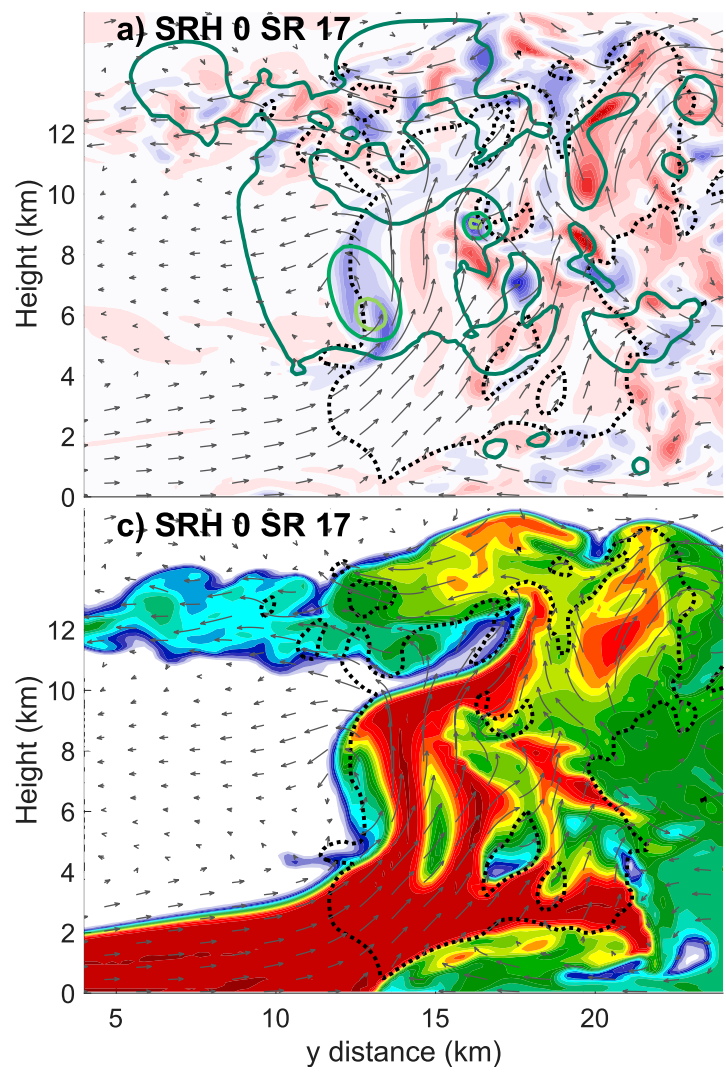

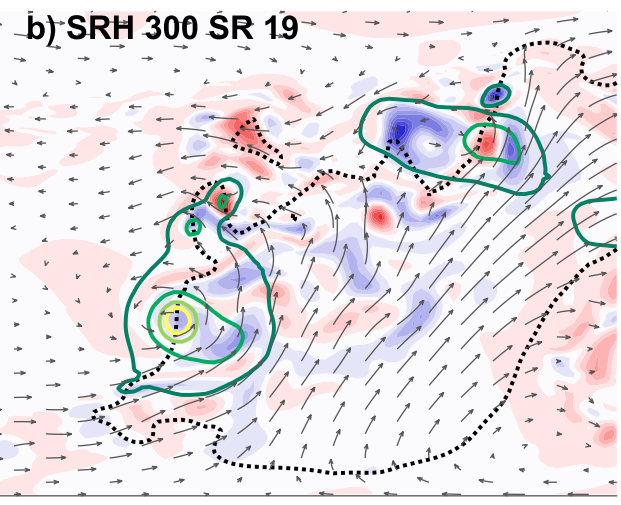

d) SRH 300 SR 19.

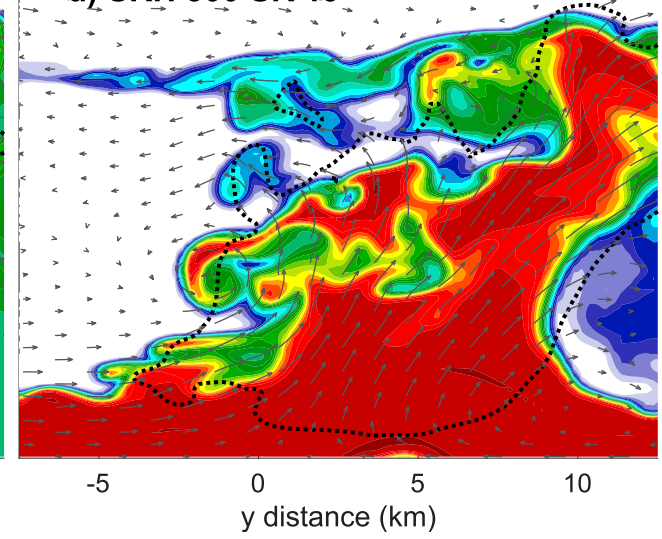

FIG. 18. Cross sections taken along the gray dashed lines in (left) Fig. 17e and (right) Fig. 17f: (a),(b) The same fields that are shown in Figs. $17 \mathrm{a}$ and $17 \mathrm{~b}$ but with pressure contours starting at $-0.5 \mathrm{hPa}$ here and with crosssection-parallel streamlines shown (gray arrows). (c),(d) The same fields that are shown in Figs. 17e,f but with the addition of streamlines (gray arrows). Note that the north-south extent of the cross sections is larger than that of the lines in Fig. 17e,f.

skill of SRH in influencing updraft properties reported by previous authors may simply occur because SRH and SR flow are correlated by definition-not because SRH is a measure of $\omega_{s}$.

- Results from simulations show that the "cutoff" between supercellular and nonsupercellular storm mode is almost entirely determined by SR flow, rather than SRH. This supports our conclusions from proximity sounding analyses.

- The primary influence of $\omega_{s}$ on the updraft properties studied here was to increase low-level (i.e., $<5 \mathrm{~km}$ AGL) $w$ and low-level rotation in environments with large $\omega_{s}$, relative to environments with small $\omega_{s}$.

- Midlevel $\zeta$ maxima within updrafts were characterized by similar magnitudes in both simulations with no EIL $\omega_{s}$, and in simulations with large EIL $\omega_{s}$. This occurred because a large portion of the air within $\zeta$ maxima originated from the tilting of midlevel vorticity.

In general, the results of this paper along with our previous studies (e.g., Peters et al. 2019, 2020b) argue that the predictive measures for tornadoes versus those for other supercell related hazards may be somewhat decoupled. For instance, SR flow may be more relevant to whether or not supercells form, and severe hazards associated with hail, damaging straight-line winds, ${ }^{5}$ and flooding. SRH, on the other hand, is more relevant than SR flow in the context of low-level mesocyclone and tornado formation. Of course, SRH and SR flow are correlated with one another, but there are conceivably environments with little hodograph curvature where SRH is small, but SR flow is large. In such environments, forecasters may erroneously underestimate the hazards related to convection if they concentrate on SRH, rather than SR flow.

There were several subjectively apparent influences of SRH on storm morphology aside from the $w, \zeta$, width, and $M$ metrics included in our statistical analysis. Storms in environments with small $\omega_{s}$ produced much deeper and more intense cold pools than those in environments

\footnotetext{
${ }^{5} \mathrm{SRH}$ may also influence damaging winds via the connection between SRH and low-level pressure accelerations.
} 

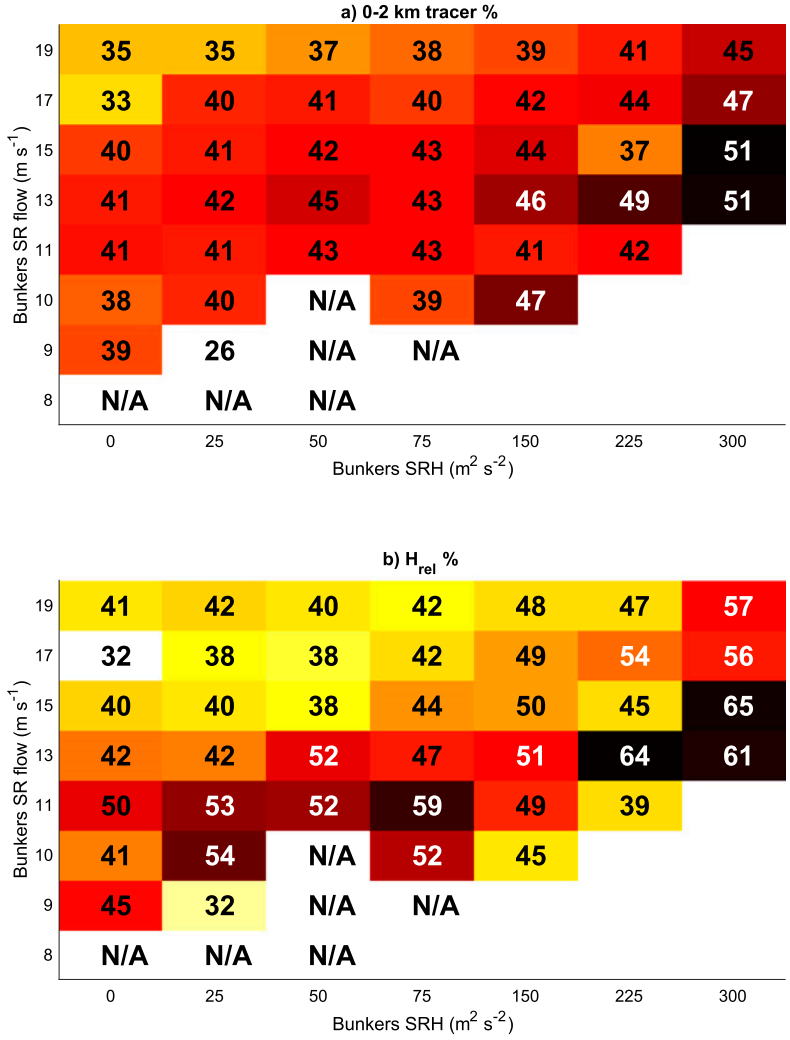

FIG. 19. The same chart layout as Fig. 6: (a) averages during the 1-3-h timeframe of the mean $0-2-\mathrm{km}$ tracer concentration (\%) within the 80 th-percentile $4-8-\mathrm{km}$ vertical vorticity at a given time. (b) As in (a), but showing $H_{\text {rel }}(\%)$.

with large $\omega_{s}$ (not shown), which potentially influences tornadogenesis (Markowski 2002; Markowski et al. 2002). Furthermore, environments with large $\omega_{s}$ seemed to promote updraft features that are more commonly associated with classic supercells than environments with small $\omega_{s}$. The reasons for these results are not quite clear and are beyond the scope of this study.

Acknowledgments. The authors are grateful for feedback from three anonymous peer reviewers. The efforts of authors J. Peters and C. Nowotarski were supported by the National Science Foundation (NSF) Grants AGS-1928666 and AGS-1928319, respectively. In addition, Peters and author J. Mulholland were partially supported by NSF Grants AGS-1841674 and Department of Energy Atmospheric System Research Grant DE-SC0000246356.

\section{REFERENCES}

Benjamin, S. G., K. J. Brundage, and L. L. Morone, 1994 Implementation of the Rapid Update Cycle. Part I: Analysis/ model description. NOAA/NWS Tech. Procedures Bull. 416, $16 \mathrm{pp}$.
Brandes, E. A., R. P. Davies-Jones, and B. C. Johnson, 1988: Streamwise vorticity effects on supercell morphology and persistence. J. Atmos. Sci., 45, 947-963, https://doi.org/10.1175/ 1520-0469(1988)045<0947:SVEOSM >2.0.CO;2.

Brooks, H. E., C. A. Doswell III, and R. Davies-Jones, 1993: Environmental helicity and the maintenance and evolution of low-level mesocyclones. The Tornado: Its Structure, Dynamics, Prediction, and Hazards, Geophys. Monogr., No. 79, Amer. Geophys. Union, 97-104.

Bryan, G. H., and J. M. Fritsch, 2002: A benchmark simulation for moist nonhydrostatic numerical models. Mon. Wea. Rev., 130, 2917-2928, https://doi.org/10.1175/1520-0493(2002)130<2917: ABSFMN $>2.0 . \mathrm{CO} ; 2$.

Bunkers, M. J., B. A. Klimowski, R. L. Thompson, and M. L. Weisman, 2000: Predicting supercell motion using a new hodograph technique. Wea. Forecasting, 15, 61-79, https://doi.org/ 10.1175/1520-0434(2000)015<0061:PSMUAN >2.0.CO;2.

Coffer, B. E., and M. D. Parker, 2017: Simulated supercells in nontornadic and tornadic VORTEX2 environments. Mon. Wea. Rev., 145, 149-180, https://doi.org/10.1175/MWR-D-160226.1.

_ and _ 2018: Is there a "tipping point" between simulated nontornadic and tornadic supercells in VORTEX2 environments? Mon. Wea. Rev., 146, 2667-2693, https://doi.org/ 10.1175/MWR-D-18-0050.1.

,-- J. M. L. Dahl, L. J. Wicker, and A. J. Clark, 2017: Volatility of tornadogenesis: An ensemble of simulated nontornadic and tornadic supercells in VORTEX2 environments. Mon. Wea. Rev., 145, 4605-4625, https://doi.org/10.1175/MWRD-17-0152.1.

,-- R. L. Thompson, B. T. Smith, and R. E. Jewell, 2019: Using near-ground storm relative helicity in supercell tornado forecasting. Wea. Forecasting, 34, 1417-1435, https://doi.org/ 10.1175/WAF-D-19-0115.1.

Dahl, J. M. L., 2017: Tilting of horizontal shear vorticity and the development of updraft rotation in supercell thunderstorms. J. Atmos. Sci., 74, 2997-3020, https://doi.org/10.1175/JAS-D17-0091.1.

—, M. D. Parker, and L. J. Wicker, 2014: Imported and stormgenerated near-ground vertical vorticity in a simulated supercell. J. Atmos. Sci., 71, 3027-3051, https://doi.org/10.1175/ JAS-D-13-0123.1.

Darkow, G. L., and D. W. McCann, 1977: Relative environmental winds for 121 tornado bearing storms. Preprints, 10th Conf. On Severe Local Storms, Omaha, NE, Amer. Meteor. Soc., 413-417.

Davies-Jones, R., 1984: Streamwise vorticity: The origin of updraft rotation in supercell storms. J. Atmos. Sci., 41, 2991-3006, https://doi.org/10.1175/1520-0469(1984)041<2991:SVTOOU> 2.0.CO;2.

, 2002: Linear and nonlinear propagation of supercell storms. J. Atmos. Sci., 59, 3178-3205, https://doi.org/10.1175/15200469(2003)059<3178:LANPOS $>2.0$. CO;2.

Droegemeier, K. K., S. M. Lazarus, and R. Davies-Jones, 1993: The influence of helicity on numerically simulated convective storms. Mon. Wea. Rev., 121, 2005-2029, https://doi.org/ 10.1175/1520-0493(1993)121<2005:TIOHON>2.0.CO;2.

Durran, D. R., and J. B. Klemp, 1983: A compressible model for the simulation of moist mountain waves. Mon. Wea. Rev., 111, 2341-2361, https://doi.org/10.1175/1520-0493(1983)111<2341: ACMFTS $>2.0 . C O ; 2$.

Fawbush, E. J., and R. C. Miller, 1954: The types of air masses in which North American tornadoes form. Bull. Amer. Meteor. Soc., 35, 154-165, https://doi.org/10.1175/1520-0477-35.4.154. 
Gropp, M. E., and C. E. Davenport, 2018: The impact of the nocturnal transition on the lifetime and evolution of supercell thunderstorms in the Great Plains. Wea. Forecasting, 33, 1045-1061, https://doi.org/10.1175/WAFD-17-0150.1.

Hernandez-Deckers, D., and S. C. Sherwood, 2016: A numerical investigation of cumulus thermals. J. Atmos. Sci., 73, 41174136, https://doi.org/10.1175/JAS-D-15-0385.1.

Houston, A. L., R. L. Thompson, and R. Edwards, 2008: The optimal bulk wind differential depth and the utility of the upper-tropospheric storm-relative flow for forecasting supercells. Wea. Forecasting, 23, 825-837, https://doi.org/ 10.1175/2008WAF2007007.1.

Klemp, J. B., 1987: Dynamics of tornadic thunderstorms. Annu. Rev. Fluid Mech., 19, 369-402, https://doi.org/10.1146/ annurev.fl.19.010187.002101.

Lebo, Z. J., and H. Morrison, 2015: Effects of horizontal and vertical grid spacing on mixing in simulated squall lines and implications for convective strength and structure. Mon. Wea. Rev., 143, 4355-4375, https://doi.org/10.1175/MWR-D-150154.1.

Maddox, R. A., 1976: An evaluation of tornado proximity wind and stability data. Mon. Wea. Rev., 104, 133-142, https://doi.org/ 10.1175/1520-0493(1976)104<0133:AEOTPW>2.0.CO;2.

Markowski, P. M., 2002: Hook echoes and rear-flank downdrafts: A review. Mon. Wea. Rev., 130, 852-876, https://doi.org/10.1175/ 1520-0493(2002)130<0852:HEARFD > 2.0.CO;2.

, J. M. Straka, and E. N. Rasmussen, 2002: Direct surface thermodynamic observations within the rear-flank downdrafts of nontornadic and tornadic supercells. Mon. Wea. Rev., 130, 1692-1721, https://doi.org/10.1175/1520-0493(2002)130<1692: DSTOWT $>2.0 . \mathrm{CO} ; 2$.

McCaul, E. W., and M. L. Weisman, 1996: Simulations of shallow supercell storms in landfalling hurricane environments. Mon. Wea. Rev., 124, 408-429, https://doi.org/10.1175/15200493(1996)124<0408:SOSSSI >2.0.CO;2.

Morrison, H., 2016: Impacts of updraft size and dimensionality on the perturbation pressure and vertical velocity in cumulus convection, Part I: Simple, generalized analytic solutions. J. Atmos. Sci., 73, 1441-1454, https://doi.org/10.1175/JAS-D15-0040.1.

_ 2017: An analytic description of the structure and evolution of growing deep cumulus updrafts. J. Atmos. Sci., 74, 809-834, https://doi.org/10.1175/JAS-D-16-0234.1.

_ , and A. Gettelman, 2008: A new two-moment bulk stratiform cloud microphysics scheme in the Community Atmosphere Model, version 3 (CAM3). Part I: Description and numerical tests. J. Climate, 21, 3642-3659, https://doi.org/10.1175/ 2008JCLI2105.1.

— and J. M. Peters, 2018: Theoretical expressions for the ascent rate of moist convective thermals. J. Atmos. Sci., 75, 16991719, https://doi.org/10.1175/JAS-D-17-0295.1.

_ G. Thompson, and V. Tatarskii, 2009: Impact of cloud microphysics on the development of trailing stratiform precipitation in a simulated squall line: Comparison of one and two-moment schemes. Mon. Wea. Rev., 137, 991-1007, https:// doi.org/10.1175/2008MWR2556.1.

_ _ J. M. Peters, W. M. Hannah, A. C. Varble, and S. E. Giangrande, 2020: Thermal chains and entrainment in cumulus updrafts. Part I: Theoretical description. J. Atmos. Sci., https://doi.org/10.1175/JAS-D-19-0243.1, in press.

Nowotarski, C. J., and A. A. Jensen, 2013: Classifying proximity soundings with self-organizing maps toward improving supercell and tornado forecasting. Wea. Forecasting, $\mathbf{2 8}$, 783-801, https://doi.org/10.1175/WAF-D-12-00125.1.

Parker, M. D., 2014: Composite VORTEX2 supercell environments from near-storm soundings. Mon. Wea. Rev., 142, 508529, https://doi.org/10.1175/MWR-D-13-00167.1.

_ _ 2017: How much does "backing aloft" actually impact a supercell? Wea. Forecasting, 32, 1937-1957, https://doi.org/ 10.1175/WAF-D-17-0064.1.

Peters, J. M., 2016: The impact of effective buoyancy and dynamic pressure forcing on vertical velocities within two-dimensional updrafts. J. Atmos. Sci., 73, 4531-4551, https://doi.org/10.1175/ JAS-D-16-0016.1.

_ C. Nowotarski, and H. Morrison, 2019: The role of vertical wind shear in modulating maximum supercell updraft velocities. J. Atmos. Sci., 76, 3169-3189, https://doi.org/10.1175/JASD-19-0096.1.

—, H. Morrison, W. M. Hannah, A. C. Varble, and S. E. Giangrande, 2020a: Thermal chains and entrainment in cumulus updrafts. Part II: Analysis of idealized simulations. J. Atmos. Sci., https://doi.org/10.1175/JAS-D-19-0244.1, in press.

—_, C. Nowotarski, and G. Mullendore, 2020b: Are supercells resistant to entrainment because of their rotation? J. Atmos. Sci., 77, 1475-1495, https://doi.org/10.1175/JAS-D-190316.1.

Rasmussen, E. N., 2003: Refined supercell and tornado forecast parameters. Wea. Forecasting, 18, 530-535, https://doi.org/ 10.1175/1520-0434(2003)18<530:RSATFP $>2.0$.CO;2.

Roberts, B., and M. Xue, 2017: The role of surface drag in mesocyclone intensification leading to tornadogenesis within an idealized supercell simulation. J. Atmos. Sci., 74, 3055-3077, https://doi.org/10.1175/JAS-D-16-0364.1.

Romps, D. M., and A. B. Charn, 2015: Sticky thermals: Evidence for a dominant balance between buoyancy and drag in cloud updrafts. J. Atmos. Sci., 72, 2890-2901, https://doi.org/10.1175/ JAS-D-15-0042.1.

Rotunno, R., and J. B. Klemp, 1982: The influence of the shearinduced pressure gradient on thunderstorm motion. Mon. Wea. Rev., 110, 136-151, https://doi.org/10.1175/1520-0493(1982) $110<0136$ :TIOTSI $>2.0 . \mathrm{CO} ; 2$.

- , and - 1985: On the rotation and propagation of simulated supercell thunderstorms. J. Atmos. Sci., 42, 271-292, https://doi.org/ 10.1175/1520-0469(1985)042<0271:OTRAPO >2.0.CO;2.

Schenkman, A. D., M. Xue, and M. Hu, 2014: Tornadogenesis in a high-resolution simulation of the 8 May 2003 Oklahoma city supercell. J. Atmos. Sci., 71, 130-154, https://doi.org/10.1175/ JAS-D-13-073.1.

Sherwood, S. C., D. Hernandez-Deckers, and M. Colin, 2013: Slippery thermals and the cumulus entrainment paradox. J. Atmos. Sci., 70, 2426-2442, https://doi.org/10.1175/JAS-D-12-0220.1.

Thompson, R. L., R. Edwards, J. A. Hart, K. L. Elmore, and P. Markowski, 2003: Close proximity soundings within supercell environments obtained from the Rapid Update Cycle. Wea. Forecasting, 18, 1243-1261, https://doi.org/10.1175/15200434(2003)018<1243:CPSWSE $>2.0$. CO;2.

_ C. M. Mead, and R. Edwards, 2007: Effective storm-relative helicity and bulk shear in supercell thunderstorm environments. Wea. Forecasting, 22, 102-115, https://doi.org/10.1175/ WAF969.1.

, B. T. Smith, J. S. Grams, A. R. Dean, and C. Broyles, 2012: Convective modes for significant severe thunderstorms in the contiguous United States. Part II: Supercell and QLCS tornado environments. Wea. Forecasting, 27, 1136-1154, https:// doi.org/10.1175/WAF-D-11-00116.1. 
Warren, R. A., H. Richter, H. A. Ramsay, S. T. Siems, and M. J. Manton, 2017: Impact of variations in upper-level shear on simulated supercells. Mon. Wea. Rev., 145, 2659-2681, https:// doi.org/10.1175/MWR-D-16-0412.1.

Weisman, M. L., and J. B. Klemp, 1982: The dependence of numerically simulated convective storms on vertical wind shear and buoyancy. Mon. Wea. Rev., 110, 504-520, https://doi.org/ 10.1175/1520-0493(1982)110<0504:TDONSC >2.0.CO;2.
, and - 1984: The structure and classification of numerically simulated convective storms in directionally varying wind shears. Mon. Wea. Rev., 112, 2479-2498, https://doi.org/ 10.1175/1520-0493(1984)112<2479:TSACON >2.0.CO;2.

, and R. Rotunno, 2000: The use of vertical wind shear versus helicity in interpreting supercell dynamics. J. Atmos. Sci., 57, 1452-1472, https://doi.org/10.1175/1520-0469(2000)057<1452: TUOVWS $>2.0 . \mathrm{CO} ; 2$. 